\title{
Inhaled, Nebulized Sodium Nitrite Protects In Murine and Porcine Experimental Models Of Hemorrhagic Shock and Resuscitation by Limiting Mitochondrial Injury.
}

Benjamin Kautza, MD ${ }^{1}$, Hernando Gomez, MD²,3, Daniel Escobar, MD ${ }^{1}$, Catherine Corey, $\mathrm{BS}^{5}$, Bilal Ataya, $\mathrm{MD}^{1}$, Jason Luciano, MD ${ }^{1}$, Ana Maria Botero, MD ${ }^{1}$, Lisa Gordon, BS ${ }^{2}$, John Brumfield, $\mathrm{BS}^{1}$, Silvia Martinez, $\mathrm{MD}^{1}$, Andre Holder, $\mathrm{MD}^{2}$, Olufunmilayo Ogundele, $\mathrm{MD}^{2}$, Michael Pinsky, MD ${ }^{2,3}$, Sruti Shiva, $\mathrm{PhD}^{4,5,{ }^{*}}$, and Brian S. Zuckerbraun, MD ${ }^{6,1,3,5,{ }^{*}}$

${ }^{1}$ Department of Surgery, ${ }^{2}$ Department of Critical Care Medicine, ${ }^{3}$ The Center for Critical Care Nephrology, and ${ }^{4}$ Department of Pharmacology \& Chemical Biology, and ${ }^{5}$ Vascular Medicine Institute, University of Pittsburgh, and ${ }^{6}$ VA Pittsburgh Healthcare System.

*These authors contributed equally.

Correspondence:

Brian S. Zuckerbraun, M.D.

Sruti Shiva, PhD
1240E BST
200 Lothrop Street
Pittsburgh, PA 15213
Phone: 412-383-5854
email: sss43@pitt.edu

F1267 PUH

200 Lothrop Street

Pittsburgh, PA 15213

Phone: 412-692-2850

email: zuckerbraunbs@upmc.edu

email: sss43@pitt.edu

Running Title: Inhaled Nitrite Protects in Hemorrhagic Shock

Funding: This work is supported by National Institutes of Health grants R01GM082830 (BSZ), UM1 HL120877-01 (BSZ), 1K12HL109068-02 (HG), Veterans Affairs Merit Award 1I01BX000566 (BSZ), Department of Defense DM102439 (BSZ), Hemophilia Center of Western Pennsylvania (SS) and UPMC Center for Military Medicine Research (SS), Center for Metabolism and Mitochondrial Medicine (SS) 


\section{Abstract}

Objective: The cellular injury that occurs in the setting of hemorrhagic shock and resuscitation (HS/R) affects all tissue types and can drive altered inflammatory responses. Resuscitative adjuncts hold the promise of decreasing such injury. Here we test the hypothesis that sodium nitrite $\left(\mathrm{NaNO}_{2}\right)$, delivered as a nebulized solution via an inhalational route, protects against injury and inflammation from HS/R. Methods: Mice underwent HS/R to a mean arterial pressure (MAP) of 20 or $25 \mathrm{mmHg}$. Mice were resuscitated with Lactated Ringers after 90-120 minutes of hypotension. Mice were randomized to receive nebulized $\mathrm{NaNO}_{2}$ via a flow through chamber (30mg in $5 \mathrm{~mL}$ PBS). Pigs $(30-35 \mathrm{~kg}$ ) were anesthetized and bled to a MAP of $30-40$ $\mathrm{mmHg}$ for 90 minutes, randomized to receive $\mathrm{NaNO}_{2}(11 \mathrm{mg}$ in $2.5 \mathrm{~mL}$ PBS) nebulized into the ventilator circuit starting 60 minutes into the hypotensive period, followed by initial resuscitation with Hextend. Pigs had ongoing resuscitation and support for up to four hours. Hemodynamic data were collected continuously. Results: $\mathrm{NaNO}_{2}$ limited organ injury and inflammation in murine hemorrhagic shock. A nitrate/nitrite depleted diet exacerbated organ injury, as well as mortality, and inhaled $\mathrm{NaNO}_{2}$ significantly reversed this effect. Furthermore, $\mathrm{NaNO}_{2}$ limited mitochondrial oxidant injury. In porcine $\mathrm{HS} / \mathrm{R}, \mathrm{NaNO}_{2}$ had no significant influence on shock induced hemodynamics. $\mathrm{NaNO}_{2}$ limited hypoxia/reoxia or HS/R-induced mitochondrial injury and promoted mitochondrial fusion. Conclusion: $\mathrm{NaNO}_{2}$ may be a useful adjunct to shock resuscitation based on its limitation of mitochondrial injury.

\section{Keywords:}

Nitrite

Mitochondria

Hemorrhage

Shock

Respiration 


\section{INTRODUCTION}

Traumatic injury is a leading cause of morbidity and mortality in the United States and worldwide $(1,2)$. These negative consequences from traumatic injury are often attributable to the hemodynamic, inflammatory and metabolic sequelae of hemorrhagic shock. Despite extensive efforts to decrease this burden, as well as several advances in the management of fluid resuscitation, and transfusion protocols, the impact of trauma and hemorrhagic shock continues to be a major economic and social burden $(3,4)$.

Mitochondrial dysfunction likely plays an important role in the development of inflammation, immune dysfunction and organ injury associated with trauma and hemorrhagic shock(5-8). Traumatic injury and hemorrhage has a major impact on multiple organs and cell types. The cellular stress associated with different inflammatory and ischemic insults is marked by alterations of energy metabolism that are initiated at the mitochondrial level. Injured mitochondria are responsible for oxidant stress and then influence other cellular processes including inflammation and immunity $(7,9)$.

Mitochondria are regulated on a number of levels, including by the gases oxygen, nitric oxide (NO) and carbon monoxide $(\mathrm{CO})(8,10-12)$. NO is a known regulator of mitochondrial function, and by itself reversibly inhibits the mitochondrial respiratory chain at complex IV and induces mitochondrial biogenesis $(10,12)$. More recently the anion nitrite $\left(\mathrm{NO}_{2}{ }^{-}\right)$was recognized as an "endocrine reservoir" of NO that functions as a NO donor via L-arginine and NOSindependent mechanisms. Nitrite is reduced to NO, typically under hypoxic or acidic conditions, either directly or enzymatically via proteins harnessing nitrite reductase function $(13,14)$. Nitrite has been demonstrated to limit apoptosis and cytotoxicity in heart, liver and brain following ischemia reperfusion (for a review see (15)). It has also been shown to mediate hypoxic pulmonary vasodilation(16), and inhaled nebulized sodium nitrite $\left(\mathrm{NaNO}_{2}\right)$ has been used to minimize vascular injury in experimental models(17). Therefore, we hypothesized that 
treatment with inhaled, nebulized $\mathrm{NaNO}_{2}$ in an animal models of hemorrhagic shock will minimize inflammation and organ injury by targeting mitochondrial function.

\section{MATERIALS AND METHODS}

Animals. All experiments were performed in accordance to the Institutional Animal Care and Use Committee of the University of Pittsburgh guidelines, under approved protocol number (13061614 and 13092382).

Murine model of hemorrhagic shock. Hemorrhagic shock was performed as described previously (18). Briefly, C57BL/6 mice (Jackson Laboratories, Bar Harbor, ME) weighing 20 to $26 \mathrm{~g}$ were anesthetized with pentobarbital (70 $\mathrm{mg} / \mathrm{kg}$ intraperitoneal). The right and left femoral arteries were cannulated. The left arterial catheter was connected to a monitor to follow mean arterial pressure (MAP) and heart rate. Sham animals were cannulated but were not subjected to hemorrhage. For moderate shock, blood was withdrawn via the right femoral artery over 10 minutes to reduce the MAP to $25 \mathrm{mmHg}$ and maintained at this pressure for 90 minutes. Mice were then resuscitated with Ringer's lactate solution ( 2 times shed blood volume) infused slowly over 15 min. Tissue and blood collection occurred at 4 or 8 hours after resuscitation. Mice were randomized to receive nebulized sodium nitrite [(Sigma-Aldrich, St Louis, MO); $30 \mathrm{mg}$ in $5 \mathrm{~mL}$ of PBS nebulized over 20 minutes via a flow through chamber] or vehicle (PBS). Nebulization began 60 minutes into the hypotensive period in this moderate model. Additionally, in some experiments mice were randomized to standard chow diet or a low nitrate/nitrite amino acid diet (AA), TD99366 (Harlan Teklad), for 3 weeks prior to experimentation.

A model of severe shock was used for survival experiments. Mice were anesthetized and surgical manipulation was the same as above. However, for this model, blood was withdrawn over 10 minutes to achieve a MAP of $20 \mathrm{mmHg}$ and maintained at this pressure for 40 minutes. Mice were then resuscitated with Ringer's lactate solution (2 times shed blood volume) infused slowly over $15 \mathrm{~min}$. Mice were randomized to receive nebulized sodium nitrite 
(30 mg in $5 \mathrm{~mL}$ of PBS nebulized over 20 minutes via a flow through chamber) or vehicle (PBS). Nebulization began 5 minutes before resuscitation in this severe model. Additionally, mice were randomized to standard chow diet or an AA diet for 3 weeks prior to experimentation. Porcine Model of Hemorrhagic Shock.

Anesthesia and Surgical preparation. The pigs were sedated using TKX (Telazol, Ketamine, Xylazine) at $1 \mathrm{ml} / 50 \mathrm{lbs}$ intramuscular injection in the thigh and transported to the surgery suite. The pigs then received oxygen and isofluorane $2-4 \%$, and underwent endotracheal intubation. Swine were ventilated on volume control mode, with tidal volume of 8$10 \mathrm{ml} / \mathrm{kg}$, inspired fraction of $\mathrm{O}_{2}$ of 0.4 and were sustained under anesthesia with isofluorane 22.5\%. The animals were monitored with EKG monitor and pulse-oximeter in the tail, and maintenance fluids ( $5 \%$ dextrose and normal saline) were started through a peripheral ear vein at $1 \mathrm{ml} / \mathrm{kg} / \mathrm{hr}$. After cleaning the surgical areas with iodopovidone, the swine were then instrumented with a right internal jugular pulmonary artery catheter through an 8 French introducer, a right femoral vein 10 French introducer and a right femoral artery triple lumen catheter. An incision was then made in the left groin to expose the rectus femoris muscle and the vastus medialis muscle to collect muscle biopsies throughout the experiment. This area was covered with wet gauze to avoid desiccation. Animals were then allowed to stabilize for 30 minutes before starting hemorrhage.

Hemorrhagic shock and resuscitation. After the 30-minute stabilization period, the swine were bled at a rate of $20 \mathrm{ml} / \mathrm{min}$ via femoral arterial catheter until the MAP decreased to 30 $\mathrm{mmHg}$. Bleeding was re-initiated at $60 \mathrm{ml} / \mathrm{min}$ if the animal was able to compensate to a MAP of $40 \mathrm{mmHg}$, and was continued until the $30 \mathrm{mmHg}$ target was reached. This step was repeated whenever compensation to $40 \mathrm{mmHg}$ was achieved in order to maintain the animals between MAP of $30-40 \mathrm{mmHg}$ for a maximum of 90 minutes. Total shed blood volume was determined throughout the duration of the experiment. Animals were resuscitated with a $1: 1$ volume of 
Hextend to shed blood volume either at 90 minutes or if they fulfilled decompensation criteria, defined as MAP below $30 \mathrm{mmHg}$ for 10 minutes or below $20 \mathrm{mmHg}$ for 10 seconds. Following initial volume infusion, further resuscitation with lactated ringer's was dictated by an algorithm based on arterial pressure waveform contour analysis-derived Stroke Volume Variation (SVV) to assess volume responsiveness (FloTrac ${ }^{T M}$, Edwards Lifesciences, LLC, Irvine, CA, USA), and aiming at re-establishing baseline MAP. Volume responsiveness was defined as an SVV > 10\%. The pigs were then observed for up to 4 hours (Figure S2). Pigs were monitored throughout for pain or distress. Pigs were euthanized by increasing to $5 \%$ inhaled isoflurane for 5 minutes, followed by a central intravenous bolus of $\mathrm{KCl} 80 \mathrm{mEq}$.

Intervention. Swine were randomly allocated to either of two groups: Standard resuscitation (Shock group) or standard resuscitation and inhaled, nebulized $\mathrm{NaNO}_{2}\left(\mathrm{NO}_{2}\right)$ group). Randomization was done in blocks of 10 animals. Of the 10 animals, two were allocated blindly to receiving sham surgery, which consisted of cannulation as previously described, without hemorrhage. Given that blinding was not possible, allocation to either group was disclosed to the investigators performing the study only after 55 minutes into the hypotensive period in order to avoid any bias during the surgical or hemorrhage phases. Animals allocated to $\mathrm{NO}_{2}$ received $11 \mathrm{mg}$ of $\mathrm{NaNO}_{2}$ in $2.5 \mathrm{ml}$ PBS nebulized directly into the ventilator circuit after 60 minutes into the shock period.

Cell culture. Primary hepatocytes were isolated and purified from C57BL/6 mice (Jackson, Bar Harbor, Maine) and cultured as described previously(19). Highly purified hepatocytes (>98\% purity and $>98 \%$ viability by trypan blue exclusion) were suspended in Williams medium E supplemented with $10 \%$ calf serum, $1 \mu \mathrm{M}$ insulin, $2 \mathrm{mM}$ I-glutamine, $15 \mathrm{mM}$ HEPES (pH 7.4), $100 \mathrm{U} / \mathrm{mL}$ penicillin, and $100 \mu \mathrm{g} / \mathrm{mL}$ streptomycin. The cells were plated on collagen-coated tissue culture plates at a density of $2 \times 10^{5}$ cells/well in 12 -well plates for cell viability analysis or $5 \times 10^{6}$ cells $/ 100-\mathrm{mm}$ dish for Western blot and enzyme assays. After $18 \mathrm{~h}$ 
of preculture, the cells were further cultured with fresh medium containing $5 \%$ calf serum and used for experiment. All cell culture experiments were repeated in at least triplicate in cells harvested from separate cell isolations. Experiments that were performed under hypoxic (1\% $\mathrm{O}_{2}$ ) conditions were carried out within a humidified anaerobic chamber (Coy Laboratory Products, Grass Lakes, Mich). The chamber was digitally set at the required $\mathrm{O}_{2}$ concentration and was maintained at $37^{\circ} \mathrm{C}$ by a thermostatic controller. Cells were exposed to $\mathrm{NaNO}_{2}$ (25$250 \mu \mathrm{M})$ under normoxic or hypoxic (1\% oxygen) conditions.

Serum measurements. Levels of the cytokines IL-6 and IL-10 were determined by enzyme-linked immunoabsorbant assay (ELISA; R\&D Systems, Minneapolis, MN) according to the manufacturer's instructions. Alanine aminotransferase (ALT) was determined using the assay kit purchased from Sigma Chemical (St. Louis, MO) per the manufacturer's instructions.

Platelet Isolation. Arterial blood samples obtained from the femoral artery of pigs via a triple lumen catheter were obtained during the hemorrhagic period and 2 hours after resuscitation. Samples were collected in citrate and the first $2 \mathrm{ml}$ of blood discarded to avoid artificial activation. Platelets were isolated by differential centrifugation as previously described(20). Briefly, whole blood was centrifuged (150xg, $10 \mathrm{~min}$ ) in the presence of $\mathrm{PGI}_{2}$ $(1 \mu \mathrm{g} / \mathrm{ml})$ to obtain platelet rich plasma (PRP). Platelets were subsequently pelleted by centrifugation (1500xg, $10 \mathrm{~min}$ ). The platelet pellets were washed with Erythrocyte Lysis buffer containing $\mathrm{PGI}_{2}$ and the final samples resuspended in modified tyrode's buffer $(20 \mathrm{mM}$ Hepes, $128 \mathrm{mM} \mathrm{NaCl}, 12 \mathrm{mM}$ bicarbonate, $0.4 \mathrm{mM} \mathrm{NaH}_{2} \mathrm{PO}_{2}, 5 \mathrm{mM}$ Glucose, $1 \mathrm{mM} \mathrm{MgCl}, 2.8 \mathrm{mM} \mathrm{KCl}, \mathrm{pH}$ 7.4). Platelet purity was confirmed by flow cytometric measurement of CD41+ cells.

Platelet Activation. Whole blood or platelets were incubated with phycoerythrin (PE)labeled mouse anti-human CD41a antibody and APC-labeled mouse anti-human CD62P antibody (30 $\min ; 2^{\circ} \mathrm{C}$ ) and then analyzed by flow cytometry (LSRFortessa with FASCDiva software; Becton Dickinson). Platelets were identified by their characteristic light scatter and CD41a antibody binding to glycoprotein Ilb/Illa. Activated platelets are reported as the 
percentage of $10,000 \mathrm{CD} 1^{+}$platelets exhibiting APC-CD62P-fluorescence as previously described(20).

Measurements of respiration. Hepatocyte and platelet mitochondrial function was determined by placing cells in XF24 cell culture plates (Seahorse Biosciences, MA, USA) in a final volume of $250 \mu \mathrm{L}$. Primary mouse hepatocytes from C57/BL6 mice were harvested and exposed to normoxia, or hypoxia $\left(1 \% \mathrm{O}_{2} ; 6\right.$ hours) and reoxia (1 hour). Hepatocytes were also treated with or without $\mathrm{NaNO}_{2}(25 \square \mathrm{M})$. Hepatocytes were washed and place in respiration

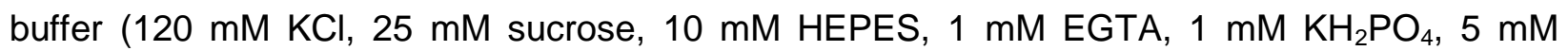
$\mathrm{MgCl}_{2}$ ). For measurement of oxygen consumption in platelets collected from pigs undergoing hemorrhagic shock, platelets were isolated from whole blood at the end of stabilization (baseline) and at the end of the observation period. Oxygen consumption rates were measured as a basal rate, as well after the addition of oligomycin $(1 \mu \mathrm{g} / \mathrm{ml})$, or FCCP $(1 \mu \mathrm{M})$ as previously described (20).

Western blot analysis. Primary mouse hepatocytes were washed with cold PBS, collected in lysis buffer, sonicated, centrifuged $(10,000 x \mathrm{xg}$ for 15 minutes) and then the supernatant transferred to a new tube. Protein concentrations were determined using the BCA protein assay kit (Pierce). Samples were then mixed with loading buffer and run on a SDSpolyacrylamide gel. This gel was then transferred to a cellulose membrane. The membrane was blocked in $5 \%$ milk for one hour and then incubated in primary antibodies. Antibodies utilized were phosphorylated (serine 656) dynamin related protein 1 (DRP-1; Cell Signaling, Danvers, MA), total DRP-1 (Cell Signaling Technology, Danvers, MA), and Mitofusin-2 (Abcam, San Francisco, CA). Membranes were then washed in TBS-Tween 20 (TBST) for 30 minutes then placed in secondary antibody for one hour and then washed for one hour in TBST prior to being developed using chemiluminescence substance (Thermo Scientific, Rockford, IL).

Aconitase Activity. Mouse liver snap-frozen 10 minutes after resuscitation or sham 
were homogenized in the manufacturer's commercial buffer, and lysates were prepared by 3 freeze/thaw cycles. Aconitase activity was determined by spectrophotometric (340 nm) monitoring of NADPH formation with the Bioxytech Aconitase-340 kit (Oxis Research, Beverly Hills, Calif).

Complex I activity. Complex I activity was determined in isolated mitochondria by spectrophotometrically $(340 \mathrm{~nm})$ monitoring the rotenone-sensitive oxidation of $100 \mu \mathrm{M} \mathrm{NADH}$ in the presence of $10 \mu \mathrm{M}$ coenzyme $Q_{1}$ in the presence and absence of $25 \mu \mathrm{M}$ rotenone as previously described(20).

Statistics. The data was analyzed using Graphpad Prism. Significance was assumed with a $\mathrm{P}<0.05$. Data is presented as mean \pm standard error of the mean. Either Students T-test for pairwise comparisons of two groups or one-way analysis of variance for significance and Tukey's post hoc test when performing pairwise comparison with multiple treatment groups. Statistical significance comparing survival was determined using the Kaplan-Meier method. Significance was established at $\mathrm{P}<0.05$.

\section{RESULTS}

Inhaled, nebulized $\mathrm{NaNO}_{2}$ protects against hemorrhage induced organ injury and systemic inflammation. The influence of $\mathrm{NaNO}_{2}$ on hemorrhage-induced organ injury was investigated in the moderate shock model in mice. Hemorrhagic shock and resuscitation led to liver and kidney injury as determined by serum ALT and cystatin C, respectively (Fig 1A, B). Nebulized $\mathrm{NaNO}_{2}$ limited organ injury $(\mathrm{P}<0.05$ compared to vehicle, treated $\mathrm{HS} / \mathrm{R}$ mice $)$. Additionally, serum IL-6 and TNFa were measured as markers of systemic inflammation (Fig 1C, D). Both of which were increased in $H S / R$, and this elevation was limited by treatment with $\mathrm{NaNO}_{2}$

A nitrite depleted diet exacerbated organ injury and death in murine $H S / R$. Approximately $50 \%$ of circulating nitrite is derived from dietary intake of nitrate or nitrite. Nitrate 
is converted to nitrite, primarily by commensal bacteria that possess nitrate reductase capabilities(14). To evaluate the contribution of endogenous nitrite as a part of a natural, physiologic response to limit cellular injury in the setting of hypoxia or ischemic type of insults, such as HS/R, dietary nitrate and nitrite were removed from the diet. Mice were fed standard chow (with nitrate or nitrite) or an amino acid (AA) diet depleted of nitrite/nitrate for 3 weeks. The nitrate/nitrite depleted diet led to exacerbated organ injury following HS/R (Fig 2A, B). Of note, inhaled, nebulized $\mathrm{NaNO}_{2}$ protected against organ injury in both standard chow and low nitrate/nitrite chow groups. Mortality was investigated in a more severe model of HS/R in which MAP was lowered to $20 \mathrm{mmHg}$ for 40 minutes followed by resuscitation with 2 times shed blood volume with $\mathrm{LR}$. Mice received nebulized vehicle or $\mathrm{NaNO}_{2}$ for 20 minutes starting 5 minutes before resuscitation in all groups. Most mortality occurred within 4 hours of resuscitation. Twenty four hour mortality was $50 \%$ in mice fed standard chow, whereas mortality was $80 \%$ in mice fed nitrate/nitrite depleted diet $(\mathrm{P}<0.05 ; \mathrm{n}=10$ mice per group) Figure 2C. With nebulized $\mathrm{NaNO}_{2}$ mortality was $20 \%$ and $30 \%$ in mice fed standard or nitrate/nitrite depleted chows, respectively $(P<0.05$ compared to shock mice fed the same respective diet). These data suggest that endogenous nitrite may play a role to limit injury in the setting of HS/R.

Sodium nitrite acts as a NO donor in the setting of hypoxia or following hemorrhagic shock ex vivo. The reduction of nitrite to NO occurs both in the blood and tissues through a variety of enzymatic and non-enzymatic pathways. Multiple enzymes possess nitrite reductase capacity that is generally favored under ischemic or hypoxic conditions(14). The ability of liver tissue to generate NO from nitrite under hypoxic conditions or following hemorrhagic shock was investigated. NO generation was significantly increased by the addition of nitrite in hypoxia (Fig 3A). Furthermore, the addition of nitrite to livers from mice that underwent hemorrhagic shock led to increased generation of NO when compared to the addition of nitrite to livers from mice that underwent sham operation (Fig 3B). Additionally, plasma and liver were harvested form mice that underwent sham operation or hemorrhage, both conditions with nebulized $\mathrm{NaNO}_{2}$. 
$\mathrm{NaNO}_{2}$ treatment was initiated 60 minutes into hemorrhage and was nebulized into the flow through chamber at $1.5 \mathrm{mg} /$ minute for 20 minutes. Mice were sacrificed 5, 10 and 30 minutes after nebulization. Plasma nitrite levels increased in the both sham and shock mice (Fig 3C). However, tissue nitrite levels were increased in the liver of mice undergoing sham operation, but did not significantly increase in the liver of shock mice (Fig 3D). Of note, baseline plasma levels of nitrite in mice fed the low NOx (AA) diet was $0.23 \pm 0.03$, which is approximately half that of mice fed standard chow.

Sodium nitrite treatment limits mitochondrial oxidative stress. $\mathrm{NaNO}_{2}$ treatment is known to influence mitochondrial complex I activity and has been shown in models of ischemia/reperfusion to limit mitochondrial oxidative stress $(21,22)$. It was next determined whether nitrite could modulate mitochondrial function and oxidative stress in a murine model of moderate HS/R. Mitochondrial ROS was specifically measured utilizing the mitochondrial specific fluorescent dye Mitosox. Liver tissue was harvested 10 minutes after fluid resuscitation. HS/R increased mitochondrial ROS production $(4.5 \pm 0.61$ fold over sham; $\mathrm{P}<0.05)$ and this was limited by $\mathrm{NaNO}_{2}$ treatment $(2.3 \pm 0.42$ fold over sham; $\mathrm{P}<0.05$ compared to HS/R; Fig 4A). Consistent with previous studies, $\mathrm{NaNO}_{2}$ also limited complex I activity (Fig 4B). Likewise, the mitochondrial enzyme aconitase, which is highly sensitive to oxidative stress, demonstrated diminished activity following HS/R (19.5 \pm 5.7 vs $39.2 \pm 5.9 \mathrm{mU} / \mathrm{mg}$ protein; $P<0.05$; Fig 4 C). This inhibition of aconitase activity was attenuated by $\mathrm{NaNO}_{2}$ treatment $(31 \pm 5.9 \mathrm{mU} / \mathrm{mg}$ protein; $\mathrm{P}<0.05$ compared to $\mathrm{HS} / \mathrm{R})$. There was no difference following $\mathrm{NaNO}_{2}$ treatment of sham mice compared to vehicle treated sham mice (not shown).

\section{Sodium nitrite influences mitochondrial respiration and dynamics in hepatocytes}

in vitro exposed to hypoxia and reoxia. To determine whether mitochondrial bioenergetics were altered by nitrite treatment, mitochondrial respiration was measured in primary hepatocytes in normoxic conditions or following in vitro hypoxia and reoxia in the presence and 
absence of $\mathrm{NaNO}_{2}$ treatment $(25 \mu \mathrm{M})$. Oxygen consumption rates were measured at baseline, with oligomycin, and FCCP as stated in Materials and Methods. Hypoxia and reoxia caused a significant decrease in maximal uncoupled respiration (FCCP stimulated), suggesting mitochondrial injury, while $\mathrm{NaNO}_{2}$ treatment completely prevented this decrease (Figure 5A, B). Hepatocytes treated with 10 fold less $\mathrm{NaNO}_{2}(2.5 \mu \mathrm{M})$ also resulted in a similar pattern to changes in oxygen consumption rates (Supplemental Fig 1). Mitochondrial respiration and health is regulated by changes in structure and dynamics. Mitochondrial fusion, which promotes the complementation of injured and non-injured mitochondria, is an adaptive response to prevent mitochondrial injury. The fusion of multiple mitochondria to form a structured intracellular mitochondrial network confers resistance to respiratory injury and loss of membrane potential $(23,24)$. Further, we have previously shown that nitrite-stimulated fusion prevents mitochondrial damage after ischemia in the heart (25). The influence of $\mathrm{NaNO}_{2}$ on mitochondrial dynamics was determined in hepatocytes in vitro. Hepatocytes were treated with or without $\mathrm{NaNO}_{2}(25 \mu \mathrm{M}$ for $30 \mathrm{~min})$ and changes in mitochondrial interconnectivity were determined by electron microscopy. $\mathrm{NaNO}_{2}$ treatment led to a significant increase in interconnectivity, suggesting increased fusion (Fig $\mathbf{5 C - E}$ ). To determine the mechanism by which nitrite increases fusion, the major regulators of mitochondrial fission and fusion were measured. A small increase that did not reach statistical significance was observed in the expression of mitofusin 2 , the predominant regulator of fusion (data not shown). However, nitrite significantly modulated dynamin related protein 1 (Drp1), the major stimulator of fission. Nitrite induced the phosphorylation of serine 656 on Drp1 (Fig 5F), a modification that inhibits the activity of the protein and thus inhibits fission. This phosphorylation could thus underlie the augmented fusion phenotype apparent in the hepatocytes. Measurement of hepatocyte viability after $H / R$ in the presence and absence of nitrite showed that $H / R$ caused cell death and this was prevented by pre-treatment with $\mathrm{NaNO}_{2}$ (Fig 5G). Furthermore, treatment with mitochondrial division inhibitor1 (mdivi-1), a pharmacological inhibitor of Drp1, reversed the protective effect of $\mathrm{NaNO}_{2}$ on 
hypoxia/reoxia-induced loss of viability (Fig $\mathbf{5 G}$ ). Together, these results suggest that nitritedependent regulation of Drp1 and subsequent mitochondrial fusion contributes to hepatocyte viability.

\section{Inhaled, low dose nebulized NaNO2 did not influence macro-hemodynamic} parameters in porcine hemorrhagic shock and resuscitation. In a model of porcine HS/R, $\mathrm{NaNO}_{2}$ had no significant influence on MAP, cardiac output, or heart rate (Figure 6). Furthermore, $\mathrm{NaNO}_{2}$ did not have any measurable effects on mixed venous oxygen saturation $\left(\mathrm{SvO}_{2}\right)$, central venous pressure (CVP), or mean pulmonary artery pressure (MPAP) when compared to animals in the shock group. The MAP target of $30 \mathrm{mmHg}$ (time point $\mathrm{H} 0$ ) was reached after a median of 33 minutes (range 23-55 minutes), with no time difference between groups.

Plasma levels of nitrite were determined in the porcine model (Figure 7). Baseline plasma nitrite levels measured $1.14 \pm 0.34 \mu \mathrm{M}$. Following nitrite nebulization, levels increased to $2.73 \pm 1.12 \mu \mathrm{M}$. Interestingly, in the hemorrhagic shock/resuscitated pigs that received inhaled $\mathrm{NaNO}_{2}$, plasma levels returned to baseline by the end of the observation period, whereas in hemorrhagic shock/resuscitated pigs without $\mathrm{NaNO}_{2}$, plasma levels rose after resuscitation and continued to rise slowly to the end of observation to a maximum of $2.94 \pm 1.23 \mu \mathrm{M}$.

Although this study was not powered to detect differences in cardiovascular collapse rates and survival, animals receiving $\mathrm{NaNO}_{2}$ showed a trend towards improved outcome. Seven pigs in the shock group $(n=15)$ hemodynamically decompensated (MAP $<30 \mathrm{mmHg}$ for 10 minutes or $<20 \mathrm{mmHg}$ for 10 seconds) requiring resuscitation prior to the 90 minute time-point or during the observation period requiring cardiopulmonary resuscitation, vs. 3 animals in the $\mathrm{NaNO}_{2}$ group $(n=12)(p=0.25)$. Similarly, 4 animals in the shock group died prior to completion of the observation period, vs. 2 pigs in the $\mathrm{NaNO}_{2}$ group $(\mathrm{p}=0.53)$. 
Inhaled, nebulized $\mathrm{NaNO}_{2}$ limited mitochondrial injury in porcine hemorrhagic shock.

Shock by definition is a failure to meet the metabolic needs of the tissue, and thus hemorrhagic shock and resuscitation is akin to a global ischemia/reperfusion type of injury (4). With the addition of trauma, this insult is potentially compounded by the release of damage associated molecular patterns (DAMPs). HS/R with or without trauma can directly impair mitochondrial function(26-29), which can underlie cellular injury and organ dysfunction. In the porcine HS/R model, the role of $\mathrm{NaNO}_{2}$ treatment on mitochondrial respiratory status in circulating platelets was determined. Platelets were chosen as a representative circulating cell that likely plays a role in multiple facets of tissue injury and inflammation in HS/R, and can easily be assayed throughout the experiment. ATP linked respiration (basal respiration minus oligomycin sensitive) was measured in platelets at baseline and at the end of the observation period (Fig $8 \mathbf{A})$. HS/R led to a decrease in ATP-linked respiration, while this was minimized by $\mathrm{NaNO}_{2}$ treatment $(P=0.18)$. Additionally $\mathrm{NaNO}_{2}$ increased mitochondrial reserve capacity (which is measured as FCCP stimulated maximal respiration minus basal respiration, Fig $8 \mathrm{~B} ; \mathrm{P}<0.05)$. These platelet mitochondrial changes were concomitant with $\mathrm{NaNO}_{2}$-induced attenuation of $\mathrm{HS} / \mathrm{R}$-induced platelet activation as measured by increased cell surface expression of CD62p by flow cytometry (HS/R showed a $2.33 \pm 0.1$ fold increase over sham pigs at a 2 hour time point following resuscitation, ${ }^{*} \mathrm{p}<0.05$; vs. $1.47 \pm 0.07$ fold increase over sham pigs; $\mathrm{P}<0.05$ compared to untreated shock and resuscitation; Fig8C).

Furthermore, mitochondrial fusion was examined in both liver and platelets in the porcine model. $\mathrm{NaNO}_{2}$ treatment was associated with an increase in phosphorylated Drp1 and Mfn2 levels (determined by Western blot) in both platelets and liver harvested 2 hours after resuscitation (Fig 9A, B). Together, these data suggest that $\mathrm{NaNO}_{2}$ potentially protects against mitochondrial injury by promoting mitochondrial complementation and fusion.

\section{DISCUSSION}


The main finding of this study is that inhaled nebulized $\mathrm{NaNO}_{2}$ as an adjunct to standard resuscitation protected against organ injury and inflammation in a murine model of HS/R. Additionally, nitrite derived from dietary sources, may be part of a normal adaptive response to prevent injury in the setting of $\mathrm{HS} / \mathrm{R} . \mathrm{NaNO}_{2}$ generates $\mathrm{NO}$ in liver tissue treated ex vivo; however, there was no influence on cardiovascular parameters and gross hemodynamics in a porcine model at the doses utilized in the in vivo studies. $\mathrm{NaNO}_{2}$ minimized mitochondrial injury in hepatocytes in vitro from hypoxia/reoxia and in vivo following HS/R in the porcine model. This protection may be in part via promoting mitochondrial adaptive responses including mitochondrial fusion.

Nitrite, which was previously thought to be solely a byproduct of NO oxidation, is now known to have bioactive properties and to serve as a circulating reservoir that is reduced to NO, typically under hypoxic or ischemic conditions(14). Recent studies have demonstrated that exogenous nitrite administration has a beneficial role in several inflammatory conditions (30-34). Nitrite has been shown to protect against focal ischemia/reperfusion injury in brain, heart, and liver in experimental models $(15,21,22,35-38)$. Additionally, in a more global ischemia/reperfusion model of cardiac arrest, nitrite has been shown to protect against cardiac and brain injury(39). Hemorrhagic shock and resuscitation represents a similar global ischemia/reperfusion type of insult. One of the major mechanisms that contribute to cellular injury in following ischemia/reperfusion type of injuries is oxidant stress $(40,41)$. These data demonstrate increased ROS generation after $\mathrm{HS} / \mathrm{R}$ and attenuation of oxidative stress with $\mathrm{NaNO}_{2}$ treatment. There are many cellular mechanisms that produce ROS, including the generation by mitochondria. Several studies have demonstrated that nitrite can posttranslationally modify and inhibit the enzymatic activity of mitochondrial complex I, a major site of mitochondrial ROS generation $(15,21,22,42)$. Consistent with these reports, these current data demonstrate increased mitochondrial ROS production and markers of oxidant stress in the 
setting of $\mathrm{HS} / \mathrm{R}$. $\mathrm{NaNO}_{2}$ limited ROS production and oxidant stress, and was also associated with inhibition of complex I.

Notably, although $\mathrm{NaNO}_{2}$ inhibited mitochondrial complex I activity, overall mitochondrial aerobic function was preserved/improved at the end of the observation period following resuscitation. This is consistent with prior studies demonstrating that nitrite-dependent inhibition of complex $\mathrm{I}$ is reversible and leads to the temporary inhibition of complex I-derived ROS, particularly at the time of reoxygenation $(21,22,39)$. In this phenomenon termed "gradual wake up", the attenuation of mitochondrial ROS generation prevents oxidation of other mitochondrial proteins, resulting in the overall protection of mitochondrial function (43).

Beyond post-translational modification, mitochondrial injury is mitigated on a number of levels, including alterations in mitochondrial morphology and dynamics. One such mechanism is mitochondrial fusion, in which intracellular networks of mitochondria are formed to prevent an overall loss of bioenergetics function due to injury of individual mitochondria(23, 24, 44). Consistent with prior studies demonstrating nitrite-mediated induction of mitochondrial fusion in other cell types $(25,45)$, increased markers of fusion were demonstrated both in vitro and in vivo. Nitrite mediated fusion appears to be due to the phosphorylation of Drp1 consistent with prior studies in which we have shown that nitrite activates protein kinase $A$, the kinase responsible for Drp1 phosphorylation $(25,45)$. Pharmacological inhibition of Drp1 and fusion prevented the protective effect of nitrite against hypoxia/reoxia induced hepatocyte cell death in vitro suggesting a central role for mitochondrial fusion in nitrite mediate protection.

The data regarding plasma and liver nitrite levels in the murine model are interesting. Coupled with data demonstrating increased hepatic NO generation following hemorrhagic shock, this suggests the rapid metabolism of $\mathrm{NO}_{2}{ }^{-}$to $\mathrm{NO}$. It is possible that $\mathrm{NaNO}_{2}$ is not being delivered to liver tissue, in the setting of shock. The porcine data, demonstrates immediate increases in plasma nitrite levels following nebulization and then a decrease to baseline following resuscitation. The finding that plasma nitrite levels increased over time following 
resuscitation in shocked pigs that did not receive $\mathrm{NaNO}_{2}$ nebulization, adds to the complexity of these findings. As hypoxia and ischemia lead to mitochondrial injury and oxidative cell stress, it is possible that with $\mathrm{NaNO}_{2}$ treatment there is less oxidative and nitrosative injury after the reperfusion seen with resuscitation (partially demonstrated in this manuscript), thus the shocked pigs that were not treated with $\mathrm{NaNO}_{2}$ would perhaps increase nitrite levels over time secondary to these mechanisms.

In addition to $\mathrm{NaNO}_{2}$ being used as a therapeutic agent, it is interesting that a diet depleted of nitrite/nitrate proved to be detrimental to animals that were later subjected to hemorrhagic shock. These data suggest that this pathway contributes to an endogenous adaptive response to limit tissue injury to an insult such as HS/R and are consistent with studies demonstrating that dietary nitrite mediates preconditioning in other models of inflammatory and/or hypoxic injury $(14,17,33,42,46,47)$. Though the mechanisms of nitrite bioactivation were not investigated in this manuscript, these data suggest that the activity of nitrite reductase enzymes may be increased in the setting of shock to utilize nitrite as a circulating reservoir of $\mathrm{NO}$ and specifically generate NO focally at a site where protection is required. Further investigations of specific mechanisms of action within cells and tissue in the setting of HS/R are warranted.

Patients suffering from hemorrhage presumably have an increased susceptibility to further hemodynamic decompensation from an agent with potential vasodilatory properties. As nitrite can be reduced to the potent vasodilator NO there are potential concerns about using this agent in the setting of hemorrhage. However, these studies did not reveal any gross measureable changes in systemic or pulmonary hemodynamics in the porcine model of hemorrhagic shock at the dose utilized in this study. Higher doses may potentially result in hypotension and be deleterious. Previous studies from Hunter et al demonstrated significant pulmonary vasodilation from inhaled nebulized nitrite at higher doses in the setting of hypoxia 
(16). Although our data suggests that the conversion of nitrite to NO occurs in this model of hemorrhagic shock, this may take place predominantly in ischemic tissues, where biologically active NO that has a relatively short half-life does not make it back into the circulation at levels high enough to influence hemodynamics. In this porcine model the delivery rate was approximately $11 \mu \mathrm{g} / \mathrm{kg} / \mathrm{min}$ for 30 minutes directly into the ventilator circuit. Similar to these data, previous studies demonstrated protective effects against tissue injury with minimal effects of blood pressure below an intravenous infusion rate of $40 \mu \mathrm{g} / \mathrm{kg} / \mathrm{min}$. However, we recognize that there is potential for precipitating hemodynamic instability at higher doses and that any therapeutic strategy involving $\mathrm{NaNO}_{2}$ must be developed with caution.

One of the potential advantages of delivering this therapy as an inhalational agent is that this could be delivered early in the field following civilian or military trauma, even prior to trained personnel establishing intravenous access. This study serves as proof of principal that this can be used to decrease tissue injury following hemorrhage via delivery into the airway in a ventilated pig or inhaled by a spontaneously ventilating mouse. In these models, animals were hypotensive and in shock prior to $\mathrm{NaNO}_{2}$ delivery and received resuscitation immediately after nebulization, thus this is clinically relevant. This agent is also an ideal resuscitative adjunct given that it is stable, transportable, low-volume, and non-flammable. The ability to deliver an agent early in the treatment strategy holds many hypothetical advantages. Dosing strategies that evaluate a range of doses and alter the timing of the dose may prove that earlier delivery is necessary for $\mathrm{NaNO}_{2}$ to be an effective therapy. The porcine model utilized is also somewhat limited to draw conclusions on the influence of $\mathrm{NaNO}_{2}$ on organ injury because there was there was only a trend toward increased organ injury in the untreated hemorrhagic shock group (data not shown) during these relatively acute time points as measured by plasma values of liver function and kidney injury.

This study opens the door for future investigations and a possible therapeutic intervention in the setting of hemorrhagic shock that may be used during the initial attention of a 
critical patient, or even in the pre-hospital setting. These experiments demonstrate a clear benefit in mitochondrial function of shocked animals, without adding unfavorable effects in an already hypotensive and critically ill individual. The advantage of ease of delivery with a low toxicity profile at these doses, might establish a novel therapy for trauma patients. 


\section{FIGURE LEGENDS}

Figure 1. $\mathrm{NaNO}_{2}$ protects against organ injury and inflammation in a murine model of hemorrhagic shock and resuscitation. Serum alanine aminotransferase (ALT; A.) and cystatin C (B.) at 4 hours after resuscitation in mice demonstrate liver and kidney injury, respectively. $\mathrm{NaNO}_{2}$ treatment protected against both liver $(134 \pm 55 \mathrm{vs} 271 \pm 78 \mathrm{IU} / \mathrm{mL})$ and kidney $(1296 \pm 485$ vs $2493 \pm 409 \mathrm{ng} / \mathrm{mL}$ ) injury. C and D. Serum TNF-alpha and IL-6 levels were also increased by hemorrhagic shock and resuscitation at a 4 hour time point $(275 \pm 43$ and $649 \pm 62 \mathrm{pg} / \mathrm{ml}$, respectively), and $\mathrm{NaNO}_{2}$ therapy attenuated levels of these cytokines $(118 \pm 25$ and $272 \pm 67$ $\mathrm{pg} / \mathrm{ml}$, respectively). Results are mean $\pm S E M$ for 8 mice per group. ${ }^{*} \mathrm{P}<0.05$ compared to sham and $\# \mathrm{P}<0.05$ compared to vehicle-treated, shock mice.

Figure 2. Levels of endogenous nitrate and nitrite contribute to a protective response against $H S / R$. Mice were fed standard chow or a diet low in nitrates and nitrites (AA diet) for 3 weeks prior to HS/R. These mice demonstrated exacerbated liver (A.) and kidney (B.) injury 4 hours after resuscitation. Therapeutic use of $\mathrm{NaNO}_{2}$ was protective in both standard chow and $\mathrm{AA}$ diet treated mice. Results are mean $\pm S E M$ for 8 mice per group. $\S \mathrm{P}<0.05$ compared to standard chow, vehicle treated shock mice; ${ }^{*} \mathrm{P}<0.05$ compared to standard chow, vehicle treated shock mice; and \#P<0.05 compared to AA diet, vehicle-treated, shock mice. C. 24 hour survival after severe hemorrhage in mice fed standard or AA diet, with and without inhaled nebulized $\mathrm{NaNO}_{2}$.

Figure 3. $\mathrm{NaNO}_{2}$ delivery increased serum nitrite $\mathrm{NO}_{2}^{-}$levels and can generate $\mathrm{NO}$. A. Fresh liver was harvested and treated with vehicle or $\mathrm{NaNO}_{2}(250 \mu \mathrm{M})$ and $\mathrm{NO}$ generation was measured. $\mathrm{NaNO}_{2}$ increased $\mathrm{NO}$ generation $(14.6 \pm 2.4$ vs $1.75 \pm 0.9 \mathrm{pmol} \mathrm{NO} / \mathrm{min} / \mathrm{mg}$ liver; $\mathrm{P}<0.05)$. B. The addition of $\mathrm{NaNO}_{2}(250 \mu \mathrm{M})$ to livers from mice that underwent hemorrhagic shock led to increased generation of NO when compared to the addition of nitrite to livers from mice that underwent sham operation $\left(11.8 \pm 2.6\right.$ vs $5.4 \pm 1.4 \mathrm{pmol} \mathrm{NO} / \mathrm{min} / \mathrm{mg}$ liver: ${ }^{*} \mathrm{P}<0.05$ compared to sham, $\mathrm{NaNO}_{2}$ treated livers and shock, vehicle treated livers). Plasma (C.) and 
liver (D.) nitrite levels were measured in sham or shock mice at baseline or 5,10 and 30 minutes following $\mathrm{NaNO}_{2}$ nebulization. Plasma levels increased in both groups over baseline $\left({ }^{*} \mathrm{P}<0.05\right)$, however, liver levels only increased in the sham treated mice $\left({ }^{*} \mathrm{P}<0.05\right.$ compared to baseline) and did not increase in those animals that were hemorrhaged, suggesting tissue metabolism.

Figure 4. $\mathrm{NaNO}_{2}$ limited hepatic mitochondrial oxidative stress. A. Hepatic mitochondrial ROS as determined by relative mitosox fluorescence was increased at 10 minutes following resuscitation and this was limited by $\mathrm{NaNO}_{2}$. B. $\mathrm{NaNO}_{2}$ further decreased $\mathrm{HS} / \mathrm{R}$ induced changes in complex I activity in liver tissue. C. Enzymatic activity of aconitase, a mitochondrial enzyme whose activity is sensitive to oxidative stress, was measured. HS/R led to a decrease in aconitase activity and $\mathrm{NaNO}_{2}$ protected against these changes. Results are mean \pm SEM for 6 mice per group ${ }^{*} \mathrm{P}<0.05$ compared to vehicle-treated sham mice; $\# \mathrm{P}<0.05$ compared to vehicletreated, shock mice).

Figure 5. Nitrite influences mitochondrial respiration and fusion. A, B. Bioenergetic profile of primary hepatocytes. Representative $\mathrm{O}_{2}$ consumption rate of primary mouse hepatocytes (A) after no treatment (green), Hypoxia/Reoxia $\left(\mathrm{H} / \mathrm{R}\right.$; red), or $\mathrm{H} / \mathrm{R}+\mathrm{NaNO}_{2}$ (blue). Right panel (B) shows quantification of several such traces. $n=5 ;{ }^{*} p<0.01 ; \# p<0.05$. C-G. Nitrite induce mitochondrial fusion. Electron microscopic images of (C) untreated or (D) nitrite treated hepatocytes. Arrows denote mitochondria. Quantification of mitochondrial interconnectivity (E) in hepatocytes treated in vitro with nitrite $(25 \mu \mathrm{M}) . \mathrm{n}=4 ; \mathrm{p}<0.01 . \quad \mathrm{NO}_{2}^{-}$phosphorylates Drp1 to mediate protection. (F) Expression of phospho and total Drp1 in hepatocytes after $\mathrm{NaNO}_{2}$ treatment. (G) Cell viability in WT (black) and cells treated with the DRP1 inhibitor MDIVI-1 (white) after $\mathrm{H} / \mathrm{R}$ in the absence and presence of nitrite pretreatment. $\mathrm{N}=5$; ${ }^{*} \mathrm{p}<0.01$.

Figure 6. $\mathrm{NaNO}_{2}$ has minimal influence on gross cardiovascular parameters in porcine hemorrhagic shock and resuscitation. Hemodynamic data are shown at time points throughout 
the experiments [baseline, end of hemorrhage $(\mathrm{H} 1), 30$ minutes into hypotension $(\mathrm{H} 30), 60$ minutes into hypotension ( $\mathrm{H} 60)$, immediately prior to resuscitation (resusc), at the end of the initial hextend bolus (hextend), 2 hours into the resuscitation (Obs2h), and 4 hours into the resuscitation (Obs4h)]. Data is shown for mean arterial pressure (MAP, A.), heart rate (B.), cardiac output (CO; C.) central venous pressure (CVP, D.), mixed venous saturation $\left(\mathrm{S}_{\mathrm{V}} \mathrm{O}_{2} \%\right.$, E.), and mean pulmonary arterial pressure (F.). Expected changes in hemodynamics are seen in shock and resuscitation, with no significant influences demonstrated in the $\mathrm{NaNO}_{2}$ treated pigs.

Figure 7. $\mathrm{NaNO}_{2}$ leads to changes in plasma levels of nitrite in porcine hemorrhagic shock and resuscitation. Nebulization of $\mathrm{NaNO}_{2}$ increaesd plasma nitrite levels ( ${ }^{\star} \mathrm{P}<0.05$ compared to baseline). In $\mathrm{NaNO}_{2}$ treated pigs, plasma nitrite levels decreased following resuscitation and decreased to baseline levels during observation, whereas non- $\mathrm{NaNO}_{2}$ treated pigs demonstrated a progressive increase in plasma nitrite levels during the observation period following resuscitation ( $\# \mathrm{P}<0.05,240$ minutes of observation compared to baseline).

Figure 8. $\mathrm{NaNO}_{2}$ protects against hemorrhagic shock and resuscitation-induced platelet activation and mitochondrial injury. A. HS/R results in decreased ATP linked respiration ( ${ }^{*} \mathrm{P}<0.05$ compared to sham), while $\mathrm{NaNO}_{2}$ treatment minimized these changes $(\mathrm{P}=0.18$ compared to HS/R). B. HS/R had a minimal effect on mitochondrial reserve capacity, however $\mathrm{NaNO}_{2}$-treated $\mathrm{HS} / \mathrm{R}$ pigs demonstrated an increase in this parameter ( ${ }^{*} \mathrm{P}<0.05$ compared to sham and HS/R) C. HS/R increased platelet activation by $2.33 \pm 0.1$ fold over sham pigs at a 2 hour time point as determined by staining for CD62p by FACS ( ${ }^{*} \mathrm{P}<0.05$ compared to sham). NaNO2 treatment limited this activation to only a $1.47 \pm 0.07$ increase over sham $(\# \mathrm{P}<0.05$ compared to HS/R). $n=7-12$ pigs per group in each experiment. 
Figure 9. Nitrite increased markers of mitochondrial fusion in porcine $H S / R$. A. Platelet levels of mitofusin 2 and phosphorylated Drp1 ( $p$-Drp1) were increased 2 hours after resuscitation in NaNO2-treated pigs that underwent HS/R. B. Likewise p-Drp1 was also increased in the liver of $\mathrm{NaNO}_{2}$ treated pigs. Western bots are representative of findings from 6-8 pigs per group. 
1. F. C. Bonnie RJ, Liverman CT (eds): Magnitude and Costs. In I. o. Medicine (ed). Washington DC: National Academy Press, 1999, pp. 41-59.

2. C. J. Carrico, J. B. Holcomb and I. H. Chaudry: Scientific priorities and strategic planning for resuscitation research and life saving therapy following traumatic injury: report of the PULSE Trauma Work Group. Acad Emerg Med 9(6):621-6, 2002.

3. M. D. Pasquale, A. B. Peitzman, J. Bednarski and T. E. Wasser: Outcome analysis of Pennsylvania trauma centers: factors predictive of nonsurvival in seriously injured patients. J Trauma 50(3):465-72; discussion 473-4, 2001.

4. A. B. Peitzman, T. R. Billiar, B. G. Harbrecht, E. Kelly, A. O. Udekwu and R. L. Simmons: Hemorrhagic shock. Curr Prob/ Surg 32(11):925-1002, 1995.

5. C. B. Cairns: Rude unhinging of the machinery of life: metabolic approaches to hemorrhagic shock. Curr Opin Crit Care 7(6):437-43, 2001.

6. I. H. Chaudry, M. Ohkawa, M. G. Clemens and A. E. Baue: Alterations in electron transport and cellular metabolism with shock and trauma. Prog Clin Biol Res 111:67-88, 1983.

7. L. N. Diebel, D. M. Liberati, A. M. Ledgerwood and C. E. Lucas: Changes in lymph proteome induced by hemorrhagic shock: the appearance of damage-associated molecular patterns. $J$ Trauma Acute Care Surg 73(1):41-50; discussion 51, 2012.

8. B. Zuckerbraun, B. Y. Chin, M. Bilban, J. Costa d'Avila, J. Rao, T. R. Billiar and L. Otterbein: Carbon monoxide signals via inhibition of cytochrome c oxidase and generation of mitochondrial reactive oxygen species. Faseb J In Press, 2007.

9. M. P. Fink, C. A. Macias, J. Xiao, Y. Y. Tyurina, R. L. Delude, J. S. Greenberger, V. E. Kagan and P. Wipf: Hemigramicidin-TEMPO conjugates: novel mitochondria-targeted antioxidants. Crit Care Med 35(9 Suppl):S461-7, 2007.

10. J. D. Erusalimsky and S. Moncada: Nitric oxide and mitochondrial signaling: from physiology to pathophysiology. Arterioscler Thromb Vasc Biol 27(12):2524-31, 2007.

11. C. A. Piantadosi and H. B. Suliman: Redox regulation of mitochondrial biogenesis. Free Radic Biol Med 53(11):2043-53, 2012.

12. S. Shiva, P. S. Brookes and V. M. Darley-Usmar: Methods for measuring the regulation of respiration by nitric oxide. Methods Cell Biol 80:395-416, 2007.

13. M. T. Gladwin, A. N. Schechter, D. B. Kim-Shapiro, R. P. Patel, N. Hogg, S. Shiva, R. O. Cannon, 3rd, M. Kelm, D. A. Wink, M. G. Espey, E. H. Oldfield, R. M. Pluta, B. A. Freeman, J. R. Lancaster, Jr., M. Feelisch and J. O. Lundberg: The emerging biology of the nitrite anion. Nat Chem Biol 1(6):308-14, 2005.

14. J. O. Lundberg, E. Weitzberg and M. T. Gladwin: The nitrate-nitrite-nitric oxide pathway in physiology and therapeutics. Nat Rev Drug Discov 7(2):156-67, 2008.

15. C. Dezfulian, N. Raat, S. Shiva and M. T. Gladwin: Role of the anion nitrite in ischemiareperfusion cytoprotection and therapeutics. Cardiovasc Res 75(2):327-38, 2007.

16. C. J. Hunter, A. Dejam, A. B. Blood, H. Shields, D. B. Kim-Shapiro, R. F. Machado, S. Tarekegn, N. Mulla, A. O. Hopper, A. N. Schechter, G. G. Power and M. T. Gladwin: Inhaled nebulized nitrite is a hypoxia-sensitive NO-dependent selective pulmonary vasodilator. Nat Med 10(10):1122-7, 2004. 
17. M. J. Alef, R. Vallabhaneni, E. Carchman, S. M. Morris, Jr., S. Shiva, Y. Wang, E. E. Kelley, M. M. Tarpey, M. T. Gladwin, E. Tzeng and B. S. Zuckerbraun: Nitrite-generated NO circumvents dysregulated arginine/NOS signaling to protect against intimal hyperplasia in Sprague-Dawley rats. J Clin Invest 121(4):1646-56, 2011.

18. C. A. McCloskey, B. S. Zuckerbraun, D. J. Gallo, Y. Vodovotz and T. R. Billiar: A role for angiotensin II in the activation of extracellular signal-regulated kinases in the liver during hemorrhagic shock. Shock 20(4):316-9, 2003.

19. M. A. West, G. A. Keller, F. B. Cerra and R. L. Simmons: Killed Escherichia coli stimulates macrophage-mediated alterations in hepatocellular function during in vitro coculture: a mechanism of altered liver function in sepsis. Infect Immun 49(3):563-70, 1985.

20. N. Cardenes, C. Corey, L. Geary, S. Jain, S. Zharikov, S. Barge, E. M. Novelli and S. Shiva: Platelet bioenergetic screen in sickle cell patients reveals mitochondrial complex $V$ inhibition, which contributes to platelet activation. Blood 123(18):2864-72, 2014.

21. E. T. Chouchani, C. Methner, S. M. Nadtochiy, A. Logan, V. R. Pell, S. Ding, A. M. James, H. M. Cocheme, J. Reinhold, K. S. Lilley, L. Partridge, I. M. Fearnley, A. J. Robinson, R. C. Hartley, R. A. Smith, T. Krieg, P. S. Brookes and M. P. Murphy: Cardioprotection by S-nitrosation of a cysteine switch on mitochondrial complex I. Nat Med 19(6):753-9, 2013.

22. S. Shiva, M. N. Sack, J. J. Greer, M. Duranski, L. A. Ringwood, L. Burwell, X. Wang, P. H. MacArthur, A. Shoja, N. Raghavachari, J. W. Calvert, P. S. Brookes, D. J. Lefer and M. T. Gladwin: Nitrite augments tolerance to ischemia/reperfusion injury via the modulation of mitochondrial electron transfer. J Exp Med 204(9):2089-102, 2007.

23. S. B. Ong, S. Subrayan, S. Y. Lim, D. M. Yellon, S. M. Davidson and D. J. Hausenloy: Inhibiting mitochondrial fission protects the heart against ischemia/reperfusion injury. Circulation 121(18):2012-22, 2010.

24. G. Twig and O. S. Shirihai: The interplay between mitochondrial dynamics and mitophagy. Antioxid Redox Signal 14(10):1939-51, 2011.

25. C. Kamga Pride, L. Mo, K. Quesnelle, R. K. Dagda, D. Murillo, L. Geary, C. Corey, R. Portella, S. Zharikov, C. St Croix, S. Maniar, C. T. Chu, N. K. Khoo and S. Shiva: Nitrite activates protein kinase $A$ in normoxia to mediate mitochondrial fusion and tolerance to ischaemia/reperfusion. Cardiovasc Res 101(1):57-68, 2014.

26. J. Tschopp: Mitochondria: Sovereign of inflammation? Eur J Immunol 41(5):1196-202, 2011.

27. K. Nakahira, J. A. Haspel, V. A. Rathinam, S. J. Lee, T. Dolinay, H. C. Lam, J. A. Englert, M. Rabinovitch, M. Cernadas, H. P. Kim, K. A. Fitzgerald, S. W. Ryter and A. M. Choi: Autophagy proteins regulate innate immune responses by inhibiting the release of mitochondrial DNA mediated by the NALP3 inflammasome. Nat Immunol 12(3):222-30, 2011.

28. S. W. Tait and D. R. Green: Mitochondria and cell signalling. J Cell Sci 125(Pt 4):807-15, 2012.

29. C. A. Piantadosi and H. B. Suliman: Transcriptional control of mitochondrial biogenesis and its interface with inflammatory processes. Biochim Biophys Acta 1820(4):532-41, 2012.

30. A. Cauwels, E. S. Buys, R. Thoonen, L. Geary, J. Delanghe, S. Shiva and P. Brouckaert: Nitrite protects against morbidity and mortality associated with TNF- or LPS-induced shock in a soluble guanylate cyclase-dependent manner. J Exp Med 206(13):2915-24, 2009.

31. C. Jadert, J. Petersson, S. Massena, D. Ahl, L. Grapensparr, L. Holm, J. O. Lundberg and M. Phillipson: Decreased leukocyte recruitment by inorganic nitrate and nitrite in microvascular inflammation and NSAID-induced intestinal injury. Free Radic Biol Med 52(3):683-92, 2012.

32. C. Jadert, M. Phillipson, L. Holm, J. O. Lundberg and S. Borniquel: Preventive and therapeutic effects of nitrite supplementation in experimental inflammatory bowel disease. Redox Biol 2:7381, 2014. 
33. K. Y. Stokes, T. R. Dugas, Y. Tang, H. Garg, E. Guidry and N. S. Bryan: Dietary nitrite prevents hypercholesterolemic microvascular inflammation and reverses endothelial dysfunction. Am J Physiol Heart Circ Physiol 296(5):H1281-8, 2009.

34. I. Yazji, C. P. Sodhi, E. K. Lee, M. Good, C. E. Egan, A. Afrazi, M. D. Neal, H. Jia, J. Lin, C. Ma, M. F. Branca, T. Prindle, W. M. Richardson, J. Ozolek, T. R. Billiar, D. G. Binion, M. T. Gladwin and D. J. Hackam: Endothelial TLR4 activation impairs intestinal microcirculatory perfusion in necrotizing enterocolitis via eNOS-NO-nitrite signaling. Proc Natl Acad Sci U S A 110(23):9451-6, 2013.

35. M. R. Duranski, J. J. Greer, A. Dejam, S. Jaganmohan, N. Hogg, W. Langston, R. P. Patel, S. F. Yet, X. Wang, C. G. Kevil, M. T. Gladwin and D. J. Lefer: Cytoprotective effects of nitrite during in vivo ischemia-reperfusion of the heart and liver. J Clin Invest 115(5):1232-40, 2005.

36. K. H. Jung, K. Chu, S. Y. Ko, S. T. Lee, D. I. Sinn, D. K. Park, J. M. Kim, E. C. Song, M. Kim and J. K. Roh: Early intravenous infusion of sodium nitrite protects brain against in vivo ischemiareperfusion injury. Stroke 37(11):2744-50, 2006.

37. K. H. Jung, K. Chu, S. T. Lee, J. S. Sunwoo, D. K. Park, J. H. Kim, S. Kim, S. K. Lee, M. Kim and J. K. Roh: Effects of long term nitrite therapy on functional recovery in experimental ischemia model. Biochem Biophys Res Commun 403(1):66-72, 2010.

38. A. Webb, R. Bond, P. McLean, R. Uppal, N. Benjamin and A. Ahluwalia: Reduction of nitrite to nitric oxide during ischemia protects against myocardial ischemia-reperfusion damage. Proc Natl Acad Sci U S A 101(37):13683-8, 2004.

39. C. Dezfulian, S. Shiva, A. Alekseyenko, A. Pendyal, D. G. Beiser, J. P. Munasinghe, S. A. Anderson, C. F. Chesley, T. L. Vanden Hoek and M. T. Gladwin: Nitrite therapy after cardiac arrest reduces reactive oxygen species generation, improves cardiac and neurological function, and enhances survival via reversible inhibition of mitochondrial complex I. Circulation 120(10):897-905, 2009.

40. M. Elias-Miro, M. B. Jimenez-Castro, J. Rodes and C. Peralta: Current knowledge on oxidative stress in hepatic ischemia/reperfusion. Free Radic Res 47(8):555-68, 2013.

41. N. J. Raat, S. Shiva and M. T. Gladwin: Effects of nitrite on modulating ROS generation following ischemia and reperfusion. Adv Drug Deliv Rev 61(4):339-50, 2009.

42. N. J. Raat, A. C. Noguchi, V. B. Liu, N. Raghavachari, D. Liu, X. Xu, S. Shiva, P. J. Munson and M. T. Gladwin: Dietary nitrate and nitrite modulate blood and organ nitrite and the cellular ischemic stress response. Free Radic Biol Med 47(5):510-7, 2009.

43. L. S. Burwell, S. M. Nadtochiy and P. S. Brookes: Cardioprotection by metabolic shut-down and gradual wake-up. J Mol Cell Cardiol 46(6):804-10, 2009.

44. T. J. Wilson, A. M. Slupe and S. Strack: Cell signaling and mitochondrial dynamics: Implications for neuronal function and neurodegenerative disease. Neurobiol Dis 51:13-26, 2013.

45. N. K. Khoo, L. Mo, S. Zharikov, C. Kamga-Pride, K. Quesnelle, F. Golin-Bisello, L. Li, Y. Wang and S. Shiva: Nitrite augments glucose uptake in adipocytes through the protein kinase A-dependent stimulation of mitochondrial fusion. Free Radic Biol Med 70:45-53, 2014.

46. N. S. Bryan, J. W. Calvert, S. Gundewar and D. J. Lefer: Dietary nitrite restores NO homeostasis and is cardioprotective in endothelial nitric oxide synthase-deficient mice. Free Radic Biol Med 45(4):468-74, 2008.

47. U. B. Hendgen-Cotta, P. Luedike, M. Totzeck, M. Kropp, A. Schicho, P. Stock, C. Rammos, M. Niessen, C. Heiss, J. O. Lundberg, E. Weitzberg, M. Kelm and T. Rassaf: Dietary nitrate supplementation improves revascularization in chronic ischemia. Circulation 126(16):1983-92, 2012. 
Figure 1.

A.
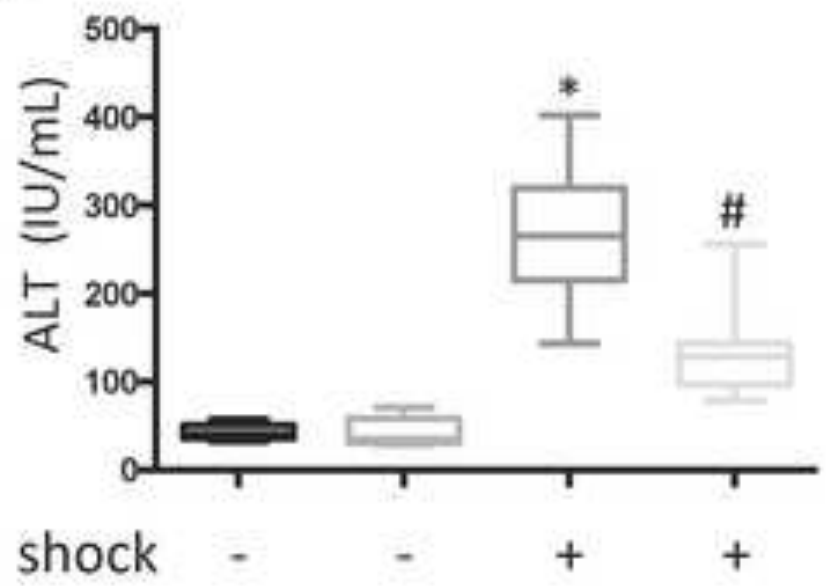

$\mathrm{NaNO}_{2}-++++$

C.

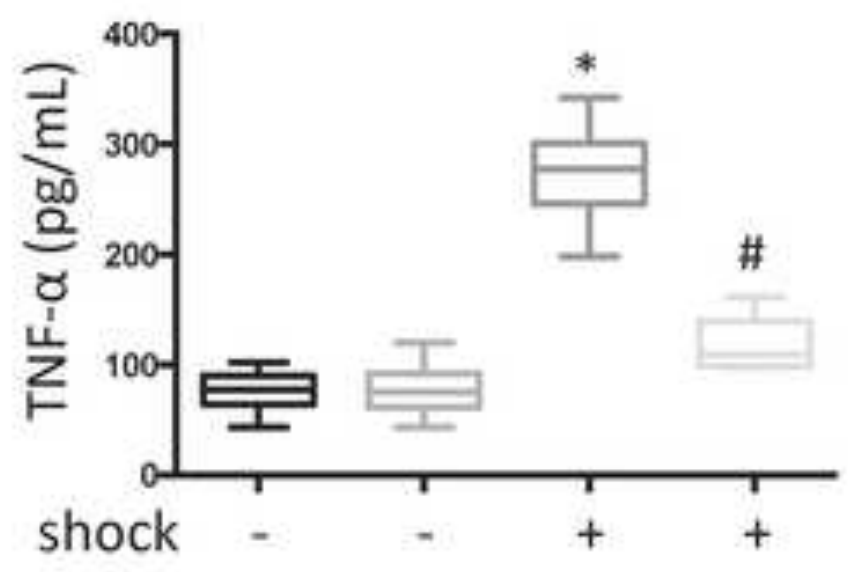

$\mathrm{NaNO}_{2}-++-+$
B.

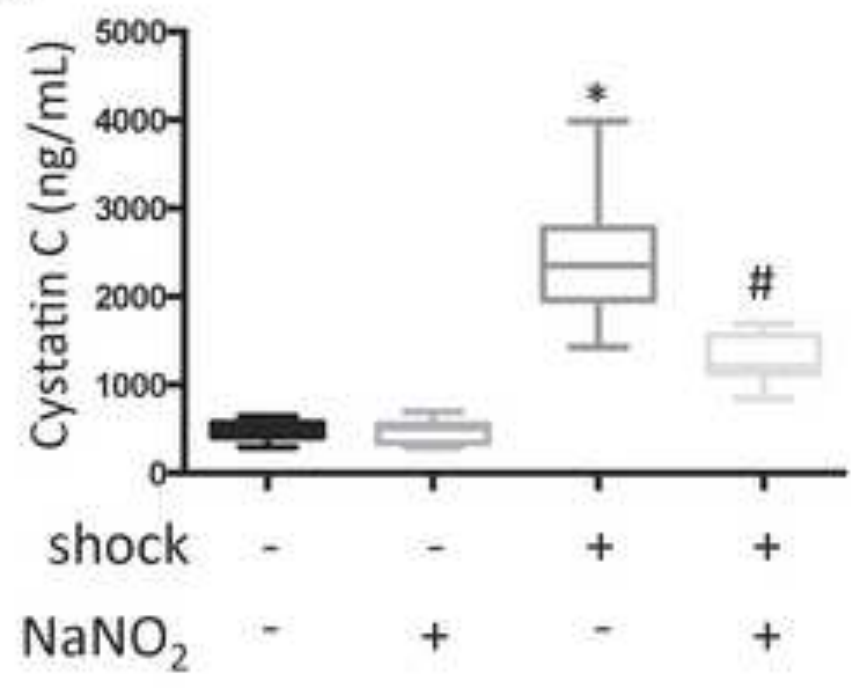

D.

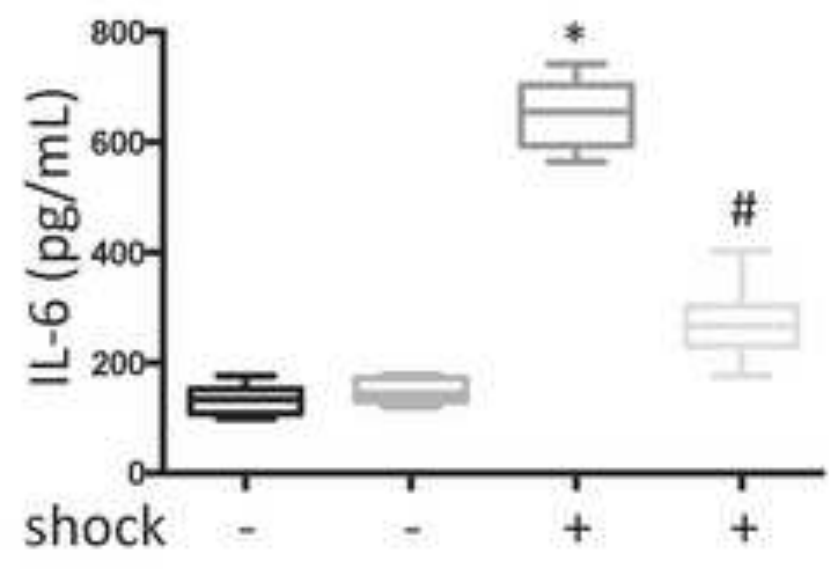

$\mathrm{NaNO}_{2}-+++$ 
Figure 2 .

A.

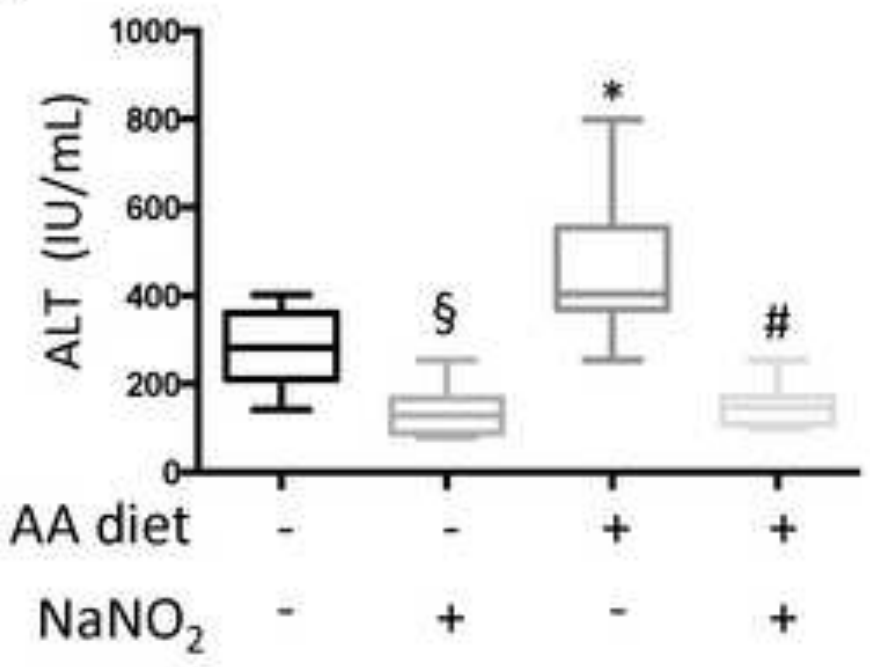

B.

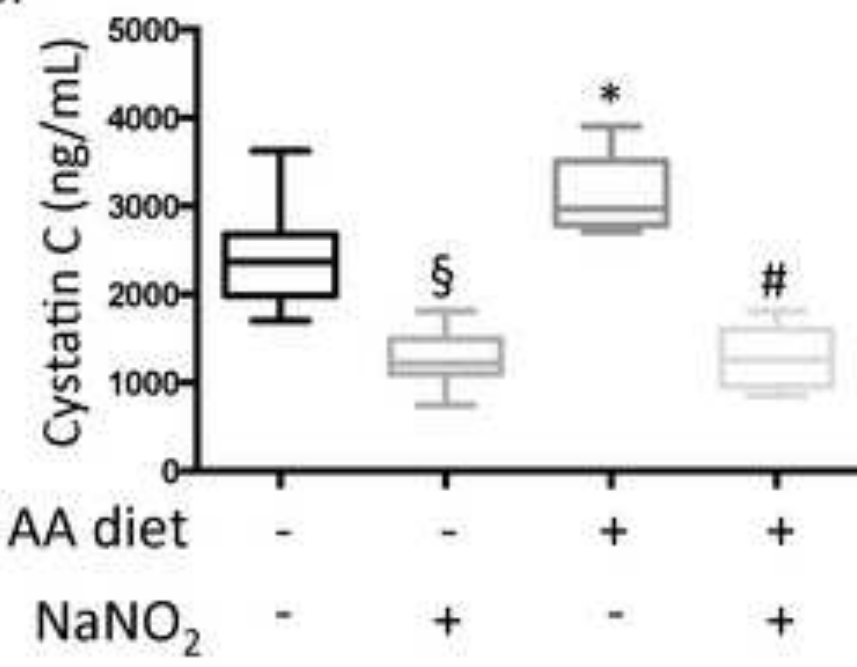

C.

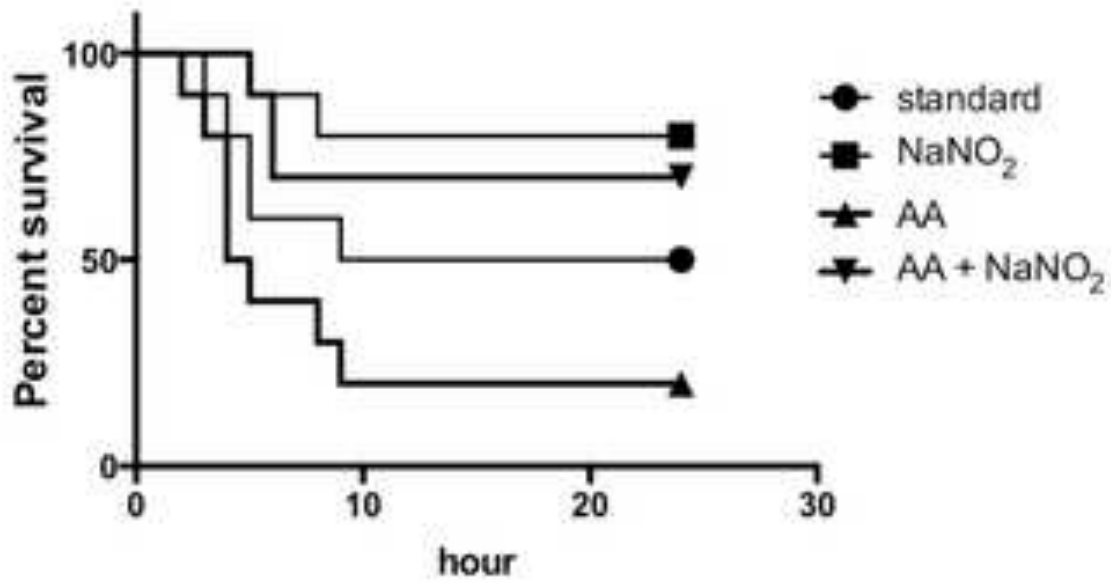


Figure 3.

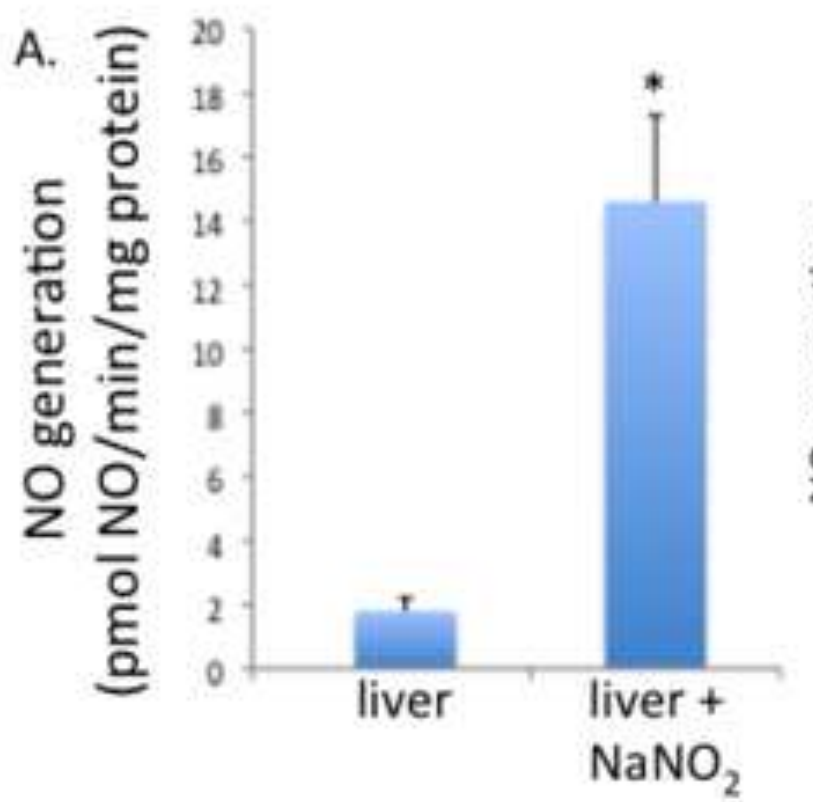

B.

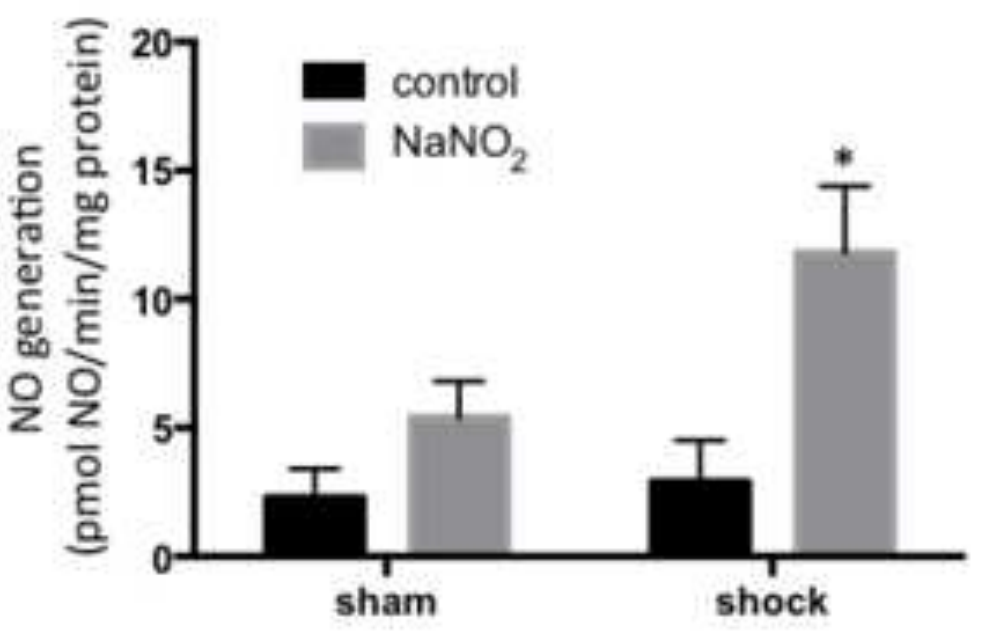

c.

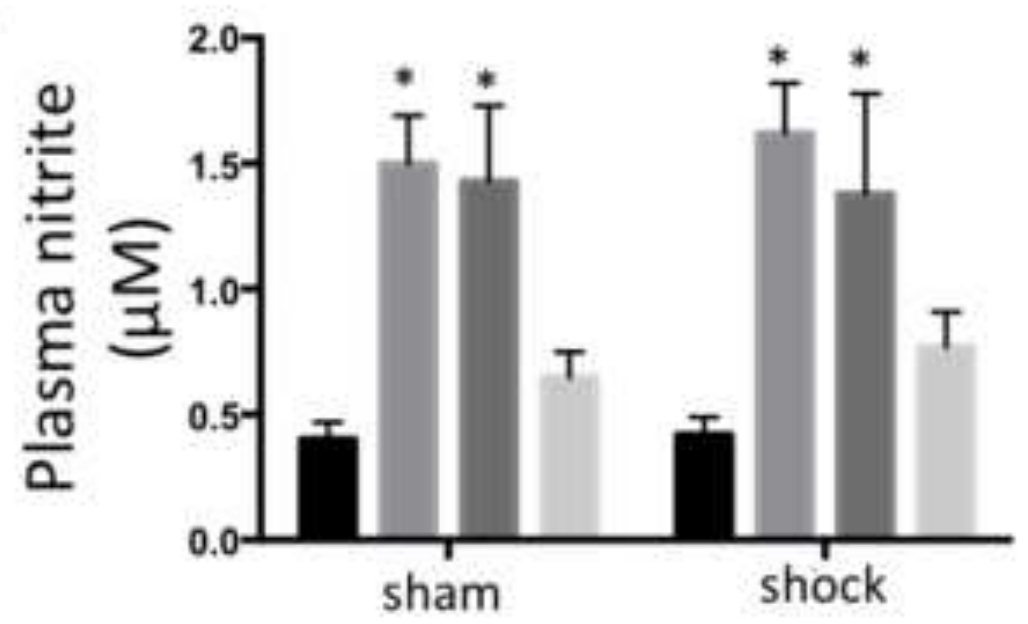

D.

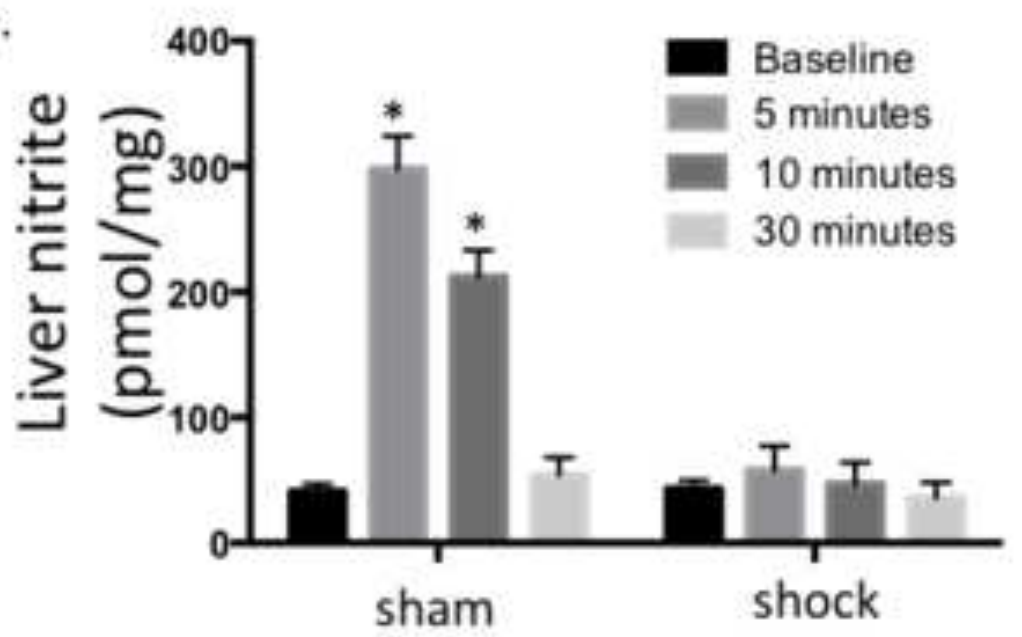


Figure 4.

A.

B.
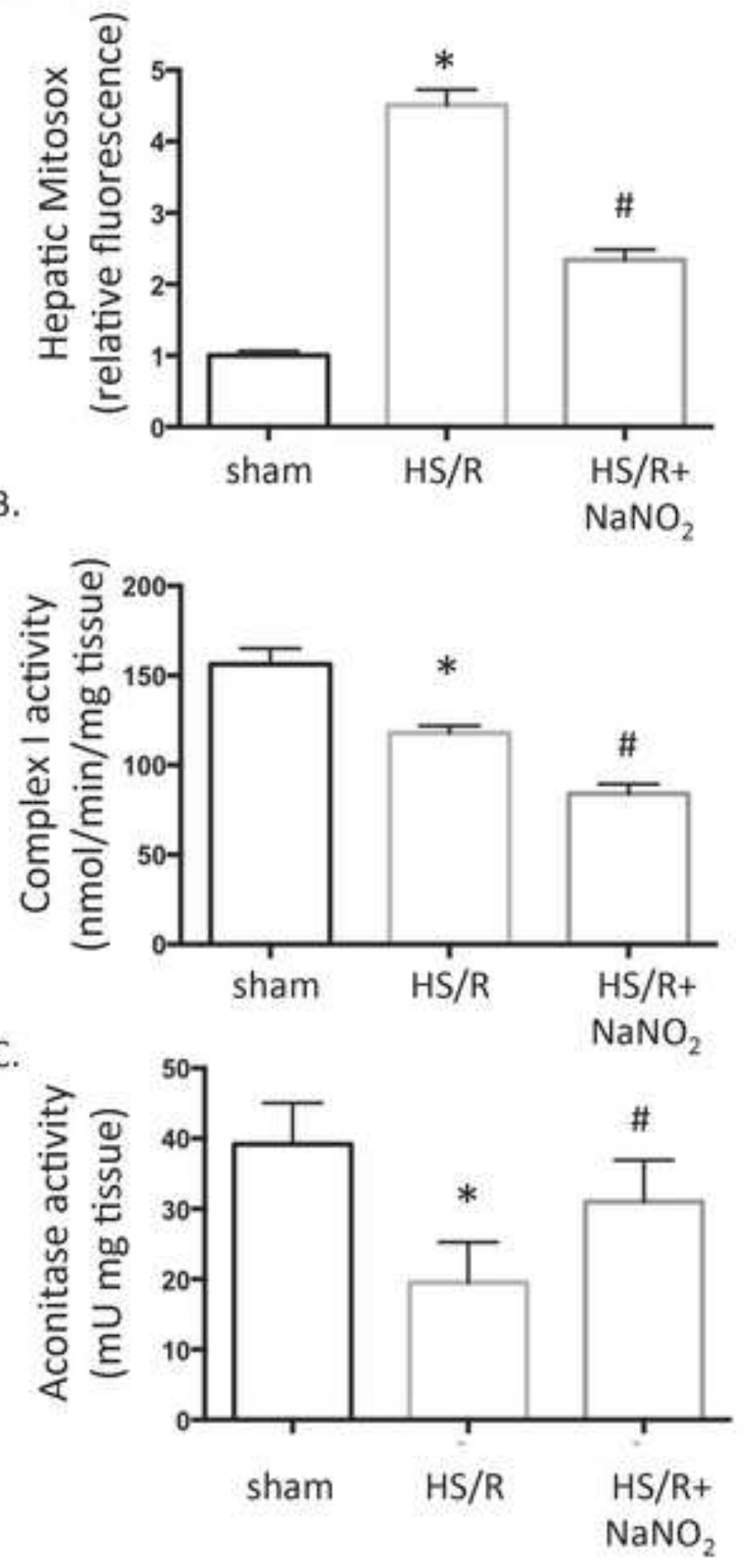
Figure 5.

A.

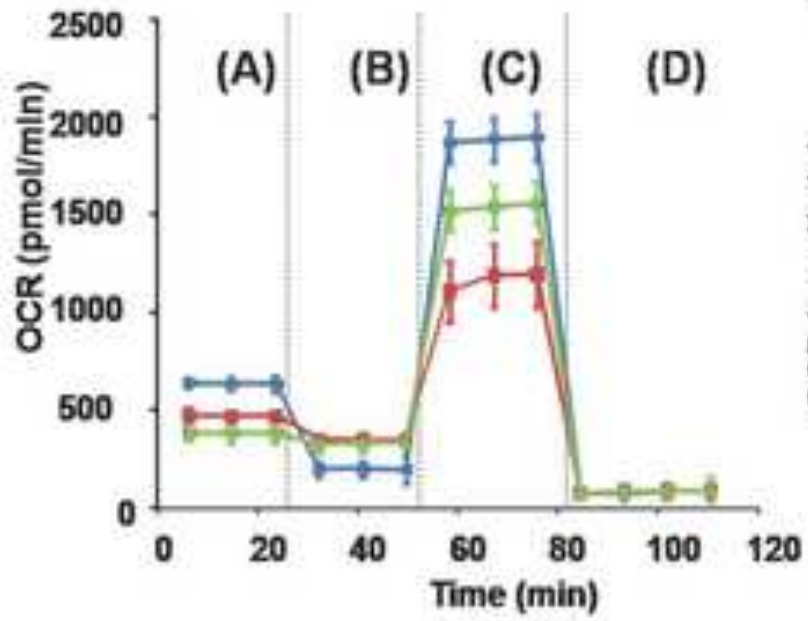

C.

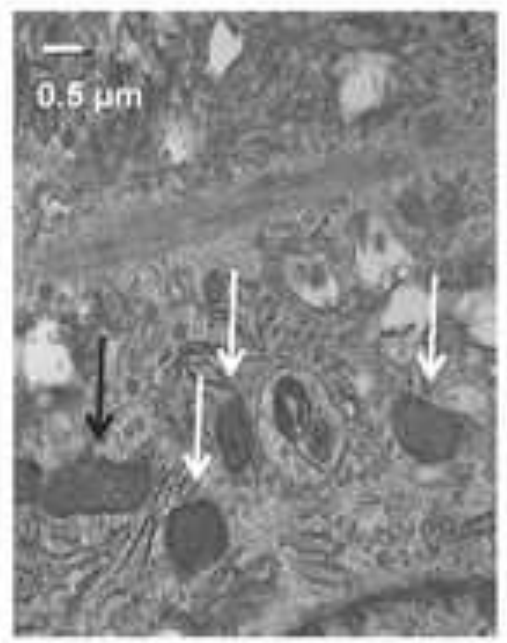

D.

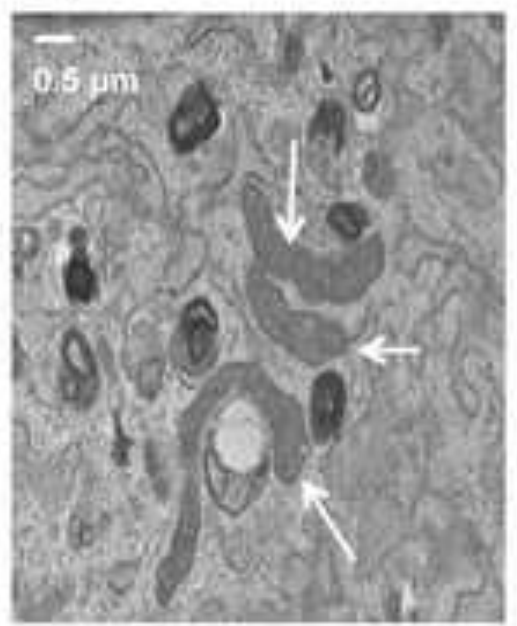

B. $2500, \mathrm{H} / \mathrm{R}+\mathrm{NaNO}_{2}$

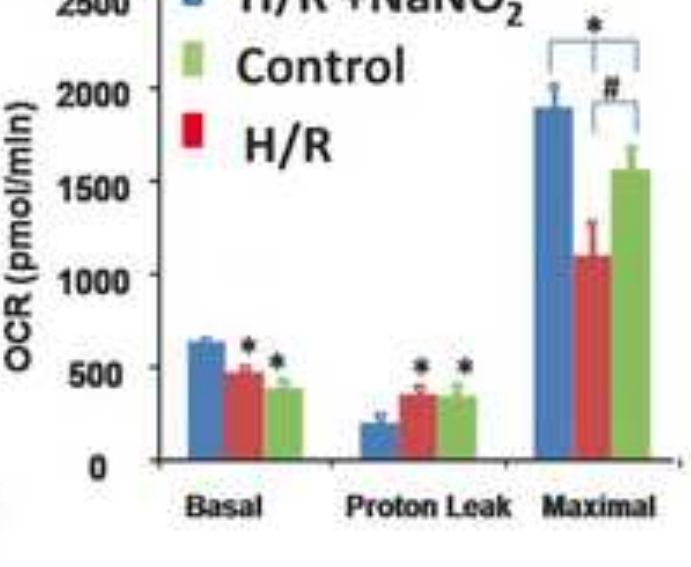

F.

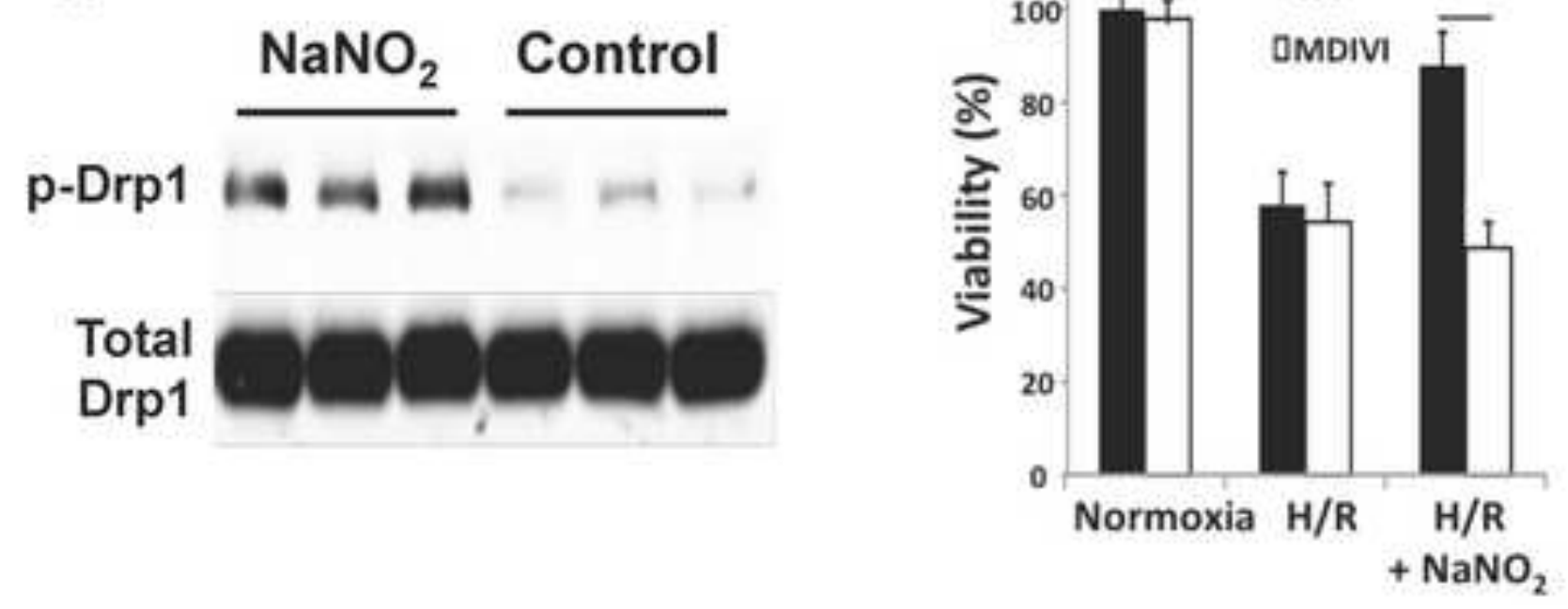


Figure 6.
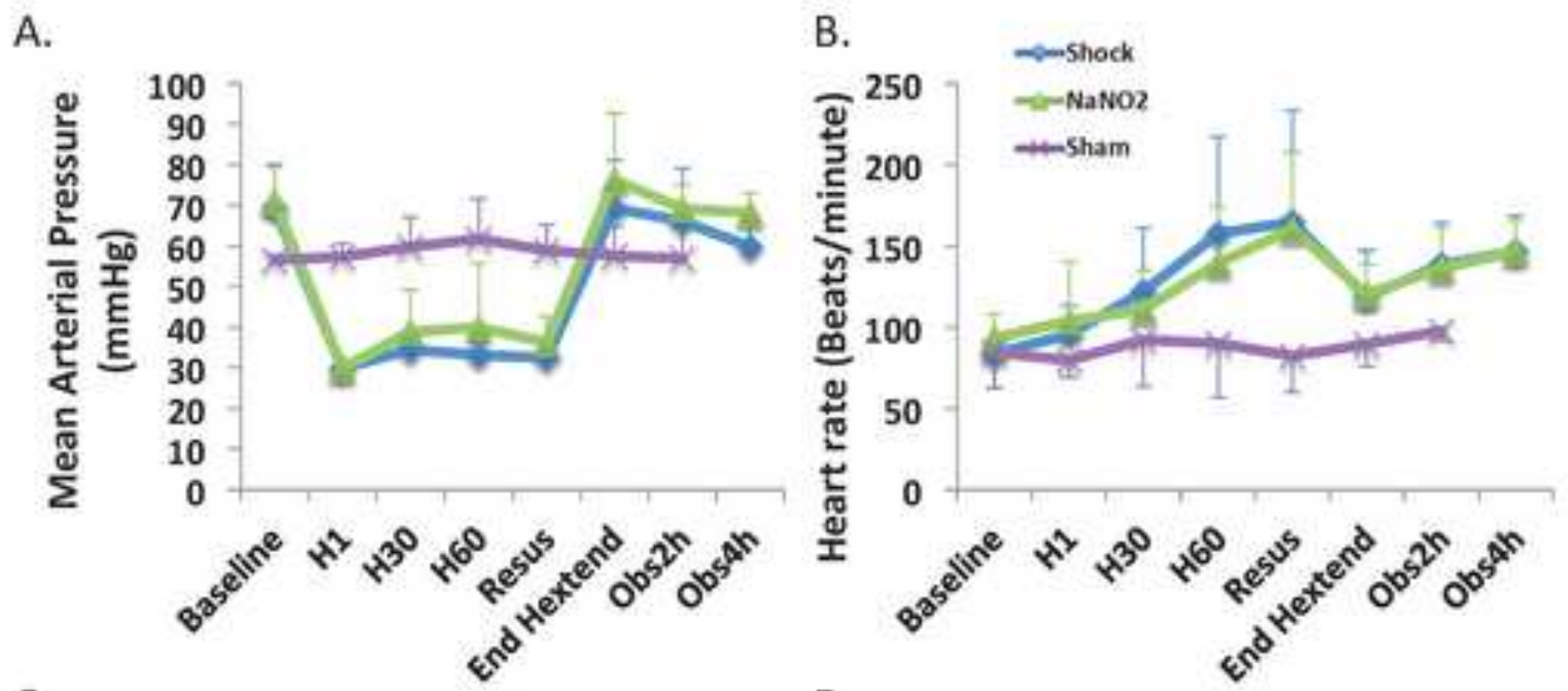

C.

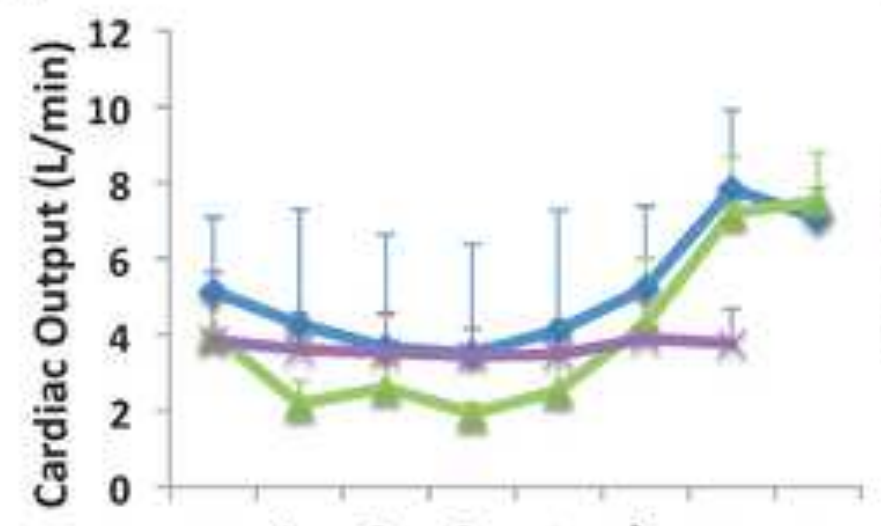

D.

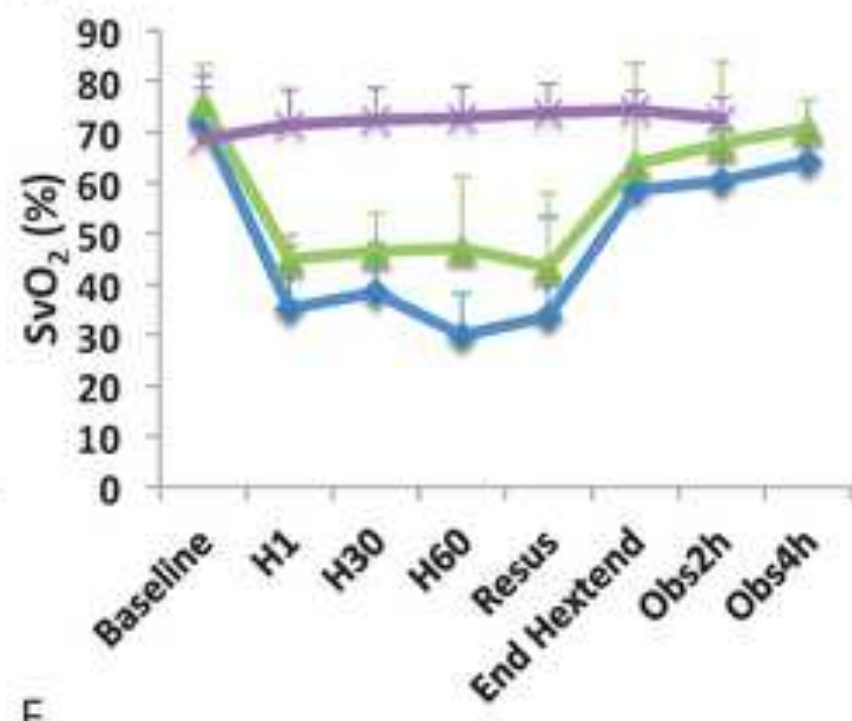

E.
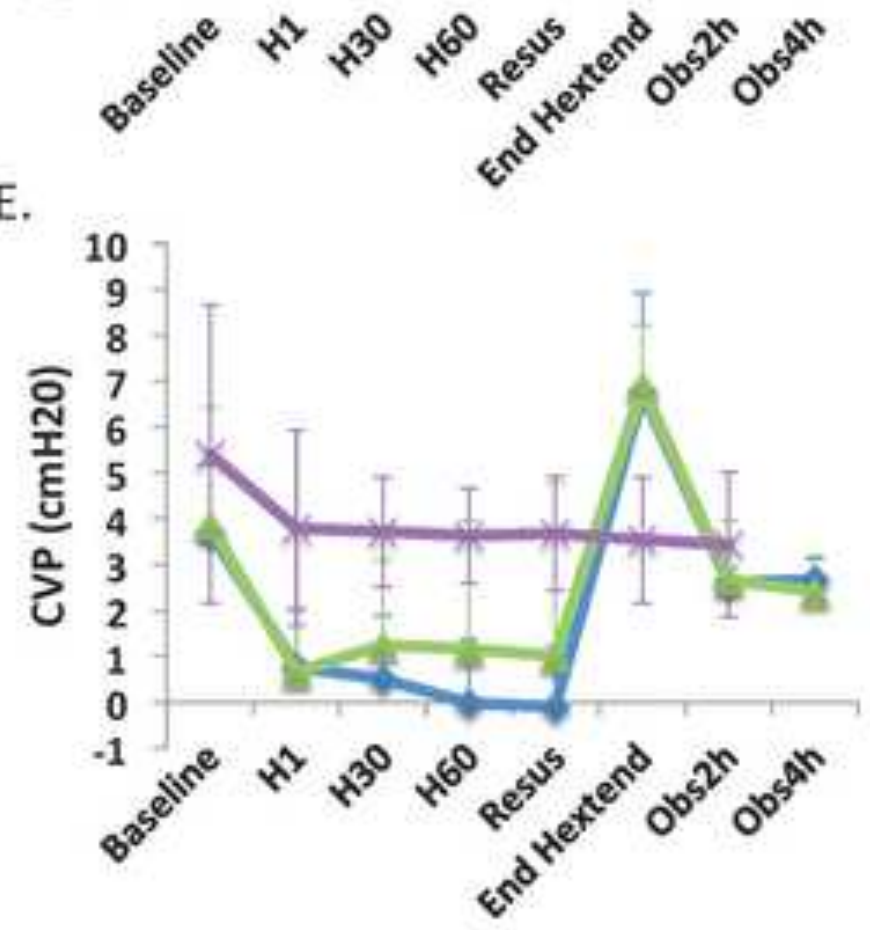

F.

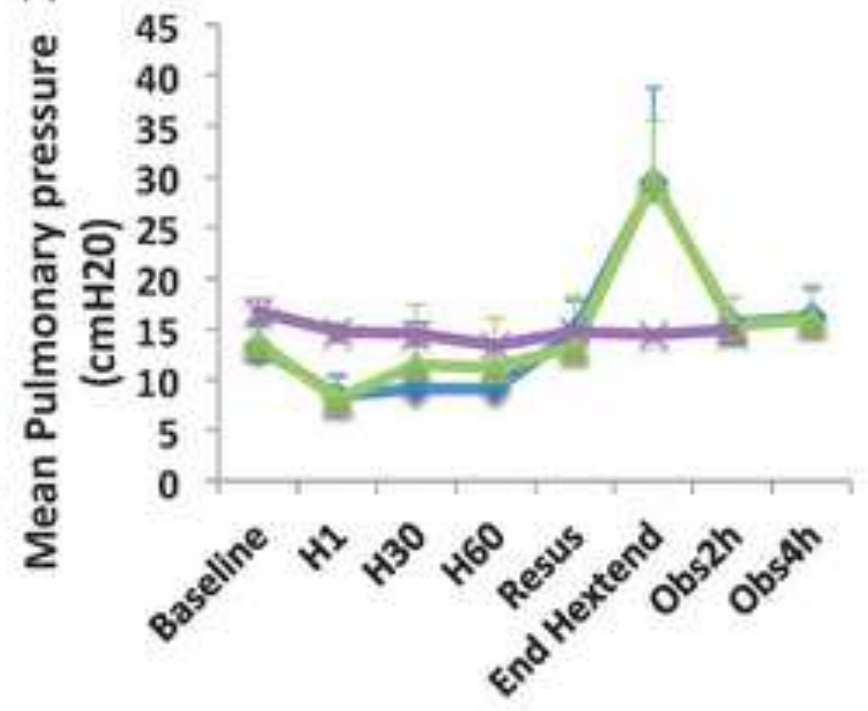


Figure 7.

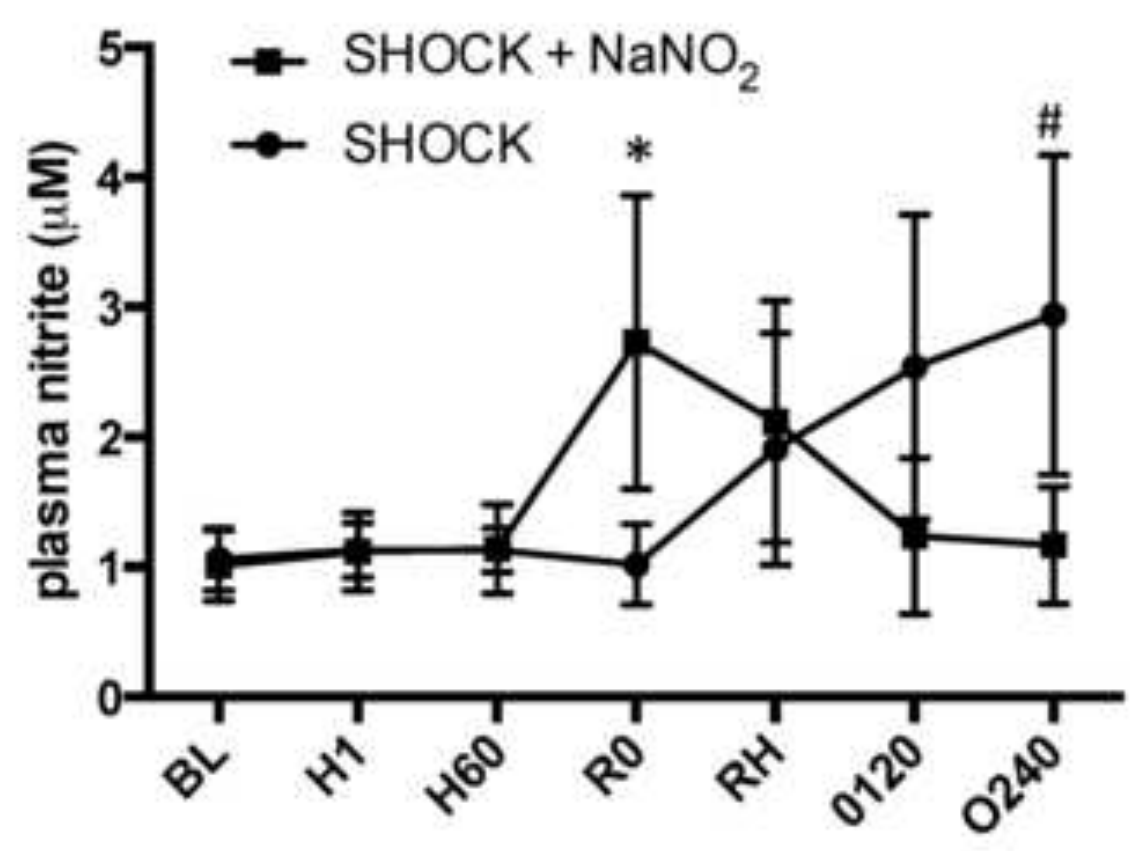


Figure 8.

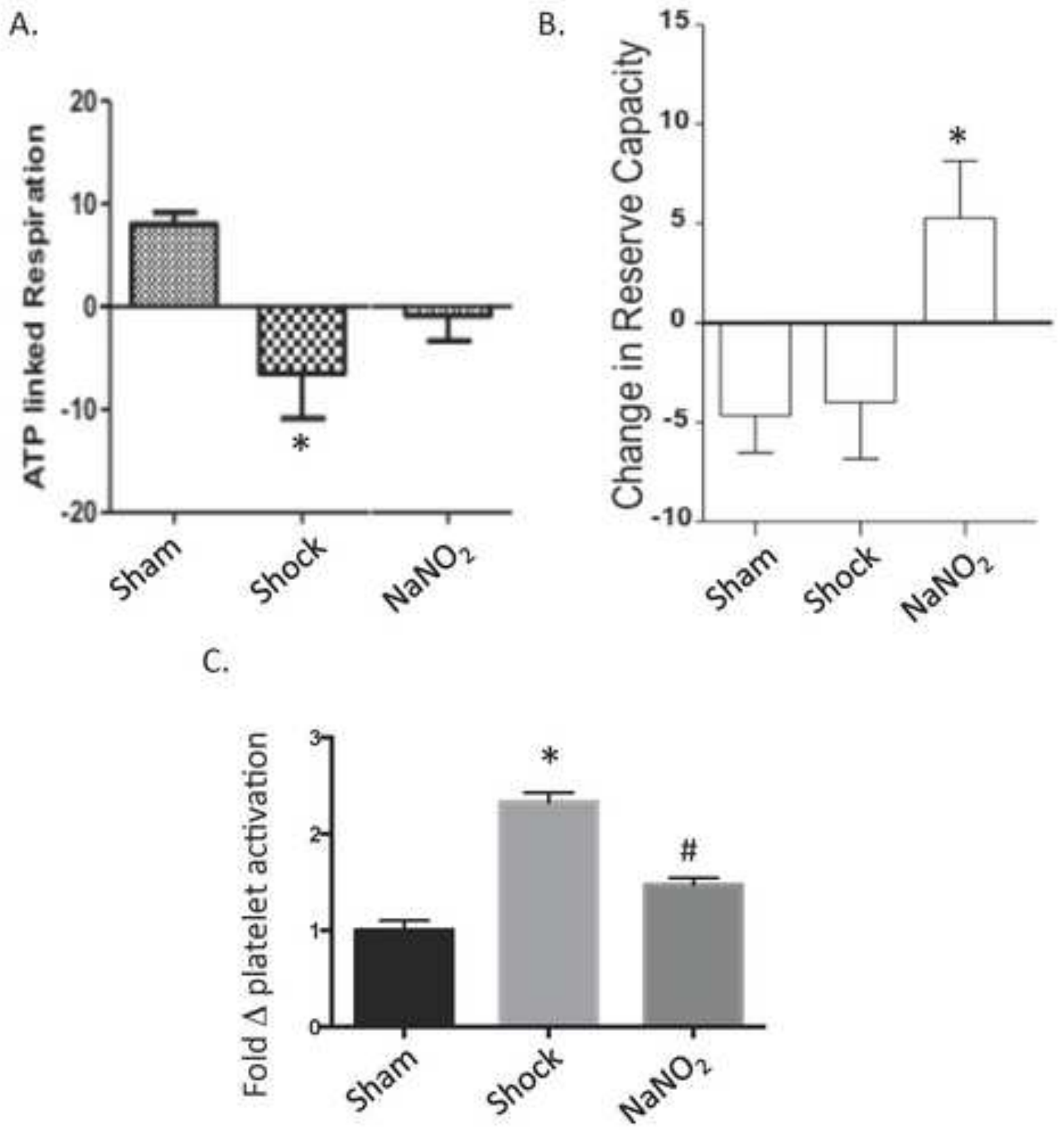


Figure 9.

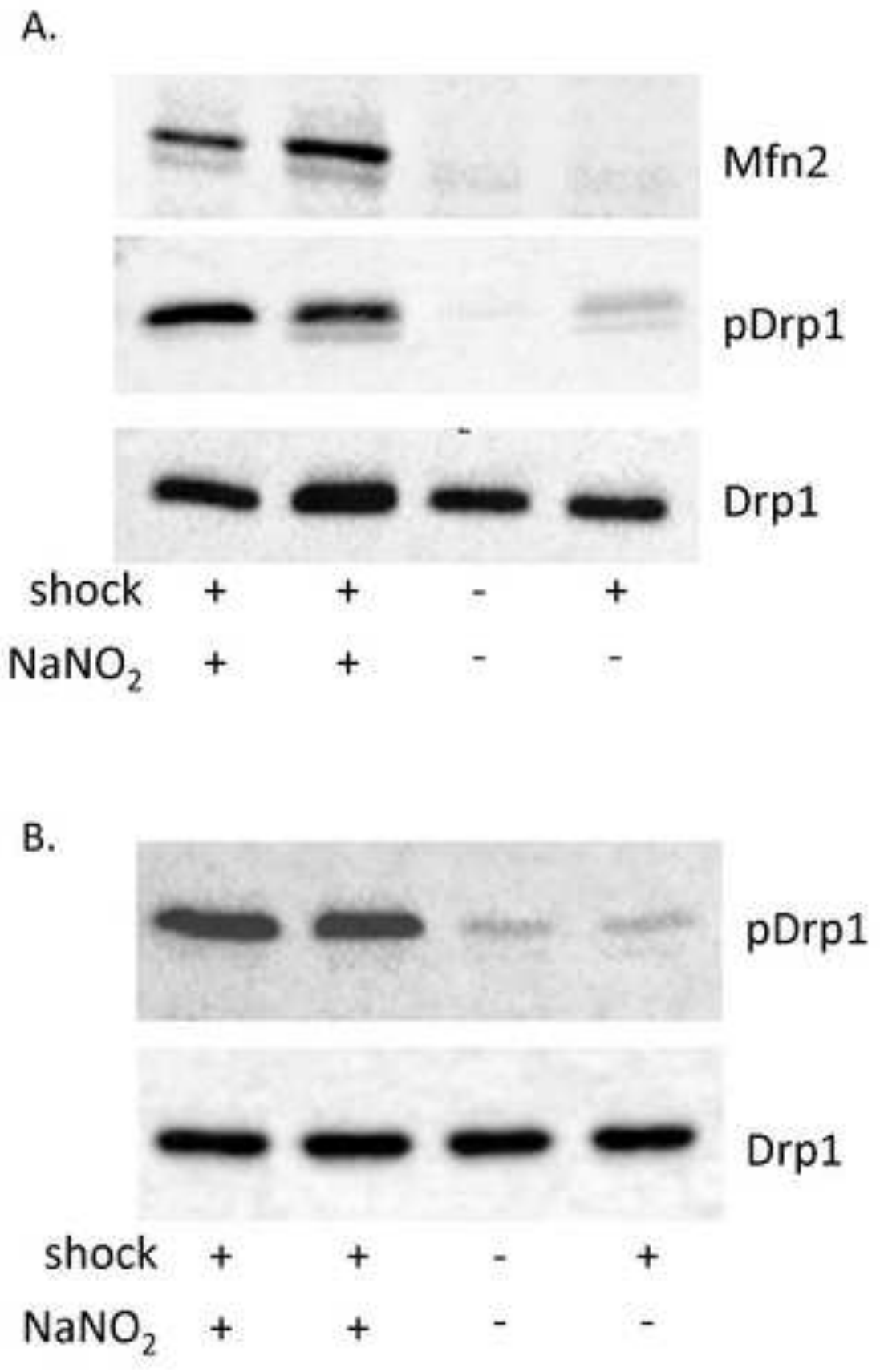

